\title{
A conjugate addition-dipolar cycloaddition approach towards the synthesis of various alkaloids
}

\author{
Andrew C. Flick and Albert Padwa* \\ Department of Chemistry, Emory University, Atlanta, GA 30322, USA \\ E-mail: chemap@emory.edu
}

\section{Dedicated to Heinz Heimgartner on the occasion of his 70th anniversary}

\begin{abstract}
The key element for the synthesis of several alkaloid skeletons consists of a conjugate additiondipolar cycloaddition of 2,3-bis(phenylsulfonyl)-1,3-butadiene with an appropriate oxime. The resulting cycloadducts are cleaved reductively to provide azapolycyclic scaffolds with strategically placed functionality for further manipulation to the target compounds.
\end{abstract}

Keywords: Conjugate addition, dipolar cycloaddition, oxime, bis(phenylsulfonyl)diene, cascade synthesis, reductive cyclization, alkaloid

\section{Table of Contents}

1. Introduction

2. Synthetic methods

2.1. Origin of the 2,3-bis(phenylsulfonyl)-1,3-butadiene mediated synthesis of piperidone derivatives

3. Alkaloid target synthesis

3.1. ( \pm )-Cylindricine $\mathrm{C}$

3.2. Approach to the perhydrohistrionicotoxin (PHTx) core

3.3. Synthesis of benzo[a]quinolizine and indolo[a]quinolizine scaffolds

3.4. Preparation of the azatricyclic core of $( \pm)$-halichlorine

4. Conclusions

5. Acknowledgements

6. References 


\section{Introduction}

Novel strategies for the stereoselective synthesis of naturally-occurring azaspirocyclic systems continue to receive considerable attention in the field of synthetic organic chemistry. ${ }^{1}$ Although methods of preparing such complex architectures such as those shown in Figure 1 vary widely, approaches which employ cycloaddition chemistry are particularly attractive given the rapid introduction of molecular complexity within a single chemical operation. ${ }^{2}$ The 1,3-dipolar cycloaddition reaction represents one of the more powerful strategies for synthesizing fivemembered azacyclic rings, since it allows up to four new stereogenic centers to be assembled in a stereospecific manner in a single step. ${ }^{3}$ When the reacting components are themselves cyclic or have ring substituents, complex multicyclic arrays, such as those contained in drugs and natural products, can be constructed in a single step and often with a high level of stereochemical control. ${ }^{4}$ In particular, the use of nitrones as 1,3-dipoles for cycloaddition chemistry has emerged as an extremely powerful method for preparing highly functionalized nitrogen heterocycles. ${ }^{5}$ Intramolecular nitrone cycloadditions have also been of considerable synthetic and mechanistic interest, since the resulting isoxazolidine ring can serve as a precursor to many 1,3-amino alcohols. ${ }^{6}$ The enantioselective version, especially when promoted by chiral Lewis acid (LA) complexes, has further enhanced its power in the synthesis of enantiomerically pure compounds. ${ }^{7}$

A significant improvement of the synthetic efficiency to a multitude of diverse heterocycles has been obtained in recent years through the development of domino reactions which allow the formation of complex compounds, starting from simple substrates, in a single transformation consisting of several steps. ${ }^{8}$ Domino reactions, multi-component reactions, and the so-called "telescoping" of reactions (the sequencing of multiple transformations in a single reaction vessel through the changing of conditions and/or adding of reagents at appropriate times) allow for the rapid increase in molecular complexity in a single chemical operation. Because of the rate at which they increase molecular complexity, the use of domino chemistry for the synthesis of alkaloids is starting to receive considerable attention from the synthetic organic community. ${ }^{9}$ The development of sequences that combine transformations of differing fundamental mechanisms broadens the scope of such procedures in synthetic chemistry. Against this backdrop, the utilization of a cascade sequence which includes a 1,3-dipolar cycloaddition reaction represents a highly useful and efficient approach toward a wide variety of azapolycyclic natural products. This mini-review contains a representative sampling from our laboratory over the past several years of the conjugate addition of oximes with 2,3bis(phenylsulfonyl)-1,3-butadiene 1 followed by a subsequent dipolar cycloaddition cascade to produce a variety of alkaloids. 

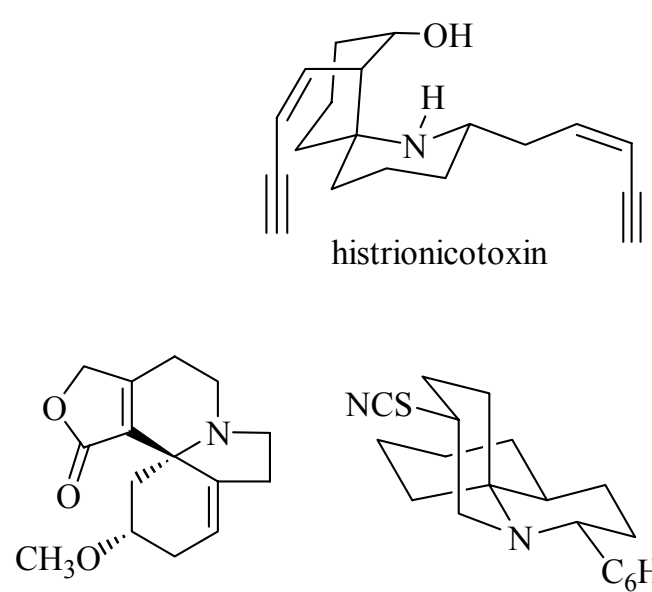

cocculodine

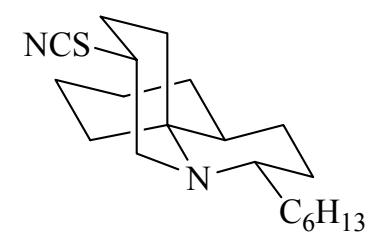

fasicularin<smiles>COc1cc2c(cc1OC)[C@@]13CC=C[C@H](OC)CC1=CC(=O)N3CC2</smiles>

erysotramidine

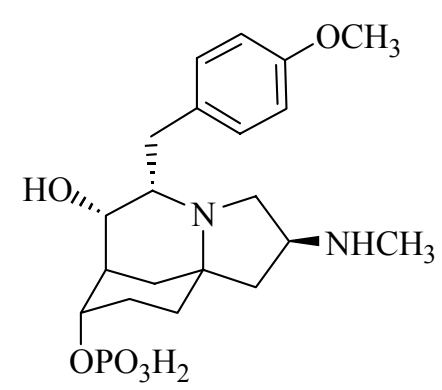

FR901483

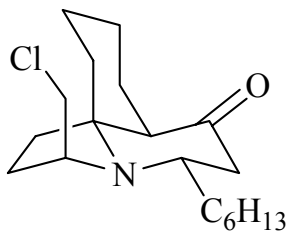

cylindricine A

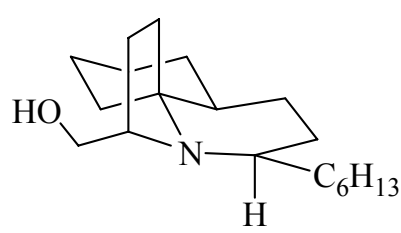

lepadiformine A<smiles>C[C@H]1/C=C/[C@H](O)/C=C(/Cl)CCOC(=O)C2=CC[C@H]3CCC[C@@H](CCC3)N2C1</smiles>

halichlorine

Figure 1. Representative alkaloid natural products.

\section{Synthetic methods}

\subsection{Origin of the 2,3-bis(phenylsulfonyl)-1,3-butadiene mediated synthesis of piperidone derivatives}

Conjugated dienes with electron-donating or electron-withdrawing substituents within the diene unit have attracted considerable attention during recent years. ${ }^{10-13}$ Sulfur-substituted dienes, in particular, have been widely used in the Diels-Alder reaction. ${ }^{14}$ The sulfur atom not only increases the reactivity of the diene but also adds control to the regioselectivity of the cycloaddition. Furthermore, the richness of synthetic transformations involving sulfur functionality make the [4+2]-adducts very useful in organic synthesis. 2,3-Bis(phenylsulfonyl)diene $\mathbf{1}$ is a crystalline compound, is easily prepared, and possesses indefinite shelf life, adding to its attractiveness as a synthetic reagent. ${ }^{15}$ In spite of its simplicity and its obvious potential as an activated diene, this compound had not been extensively utilized for organic synthesis prior to $1990 .{ }^{16}$ The phenylsulfonyl group is an extremely useful functionality in organic synthesis since it can enhance chemical reactivity and then be easily removed to provide 
sulfur-free compounds. Diene 1 can be easily prepared by a modification of the procedure of Okamura and Jeganathan in multigram quantities. 17 Thus, treatment of 2-butyne-1,4-diol with benzenesulfenyl chloride produced the disulfenate ester as a transient species, which rapidly undergoes a series of 2,3-sigmatropic rearrangements to give the corresponding divinyl sulfoxide. This material could be readily oxidized to the corresponding phenylsulfonyldiene $\mathbf{1}$ with MCPBA in excellent yield (Scheme 1). ${ }^{15}$

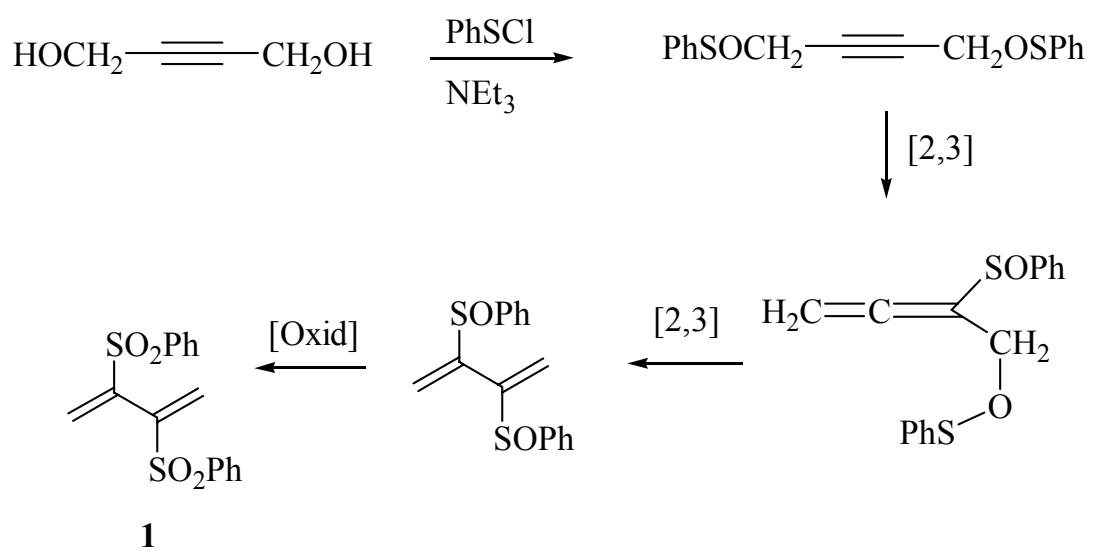

Scheme 1. Preparation of 2,3-bis(phenylsulfonyl)-1,3-butadiene 1.

In the late 1960's, Ochiai and co-workers reported the first example of an oxime reacting with an electron deficient alkene to furnish a substituted nitrone. ${ }^{18}$ Once formed, the nitrone was observed to undergo both inter- and intramolecular 1,3-dipolar cycloaddition (Scheme 2). Shortly thereafter, the Grigg group exploited this methodology for the synthesis of various nitrogen-containing heterocycles, further establishing the concept that nitrones could be readily formed by treating oximes with various electrophilic reagents. ${ }^{19}$ Inspired by the facility with which oximes react with various electrophiles to afford nitrones as reported by Ochiai 18 and Grigg ${ }^{19}$, an extension of this methodology to 2,3-bis(phenylsulfonyl)butadiene 1 seemed both logical and intriguing. We soon discovered that treating various aldehyde and keto oximes 2 with phenylsulfonyldiene 1 resulted in the formation of cycloadducts of type $\mathbf{4}$ in high yield (Scheme 3). 20 


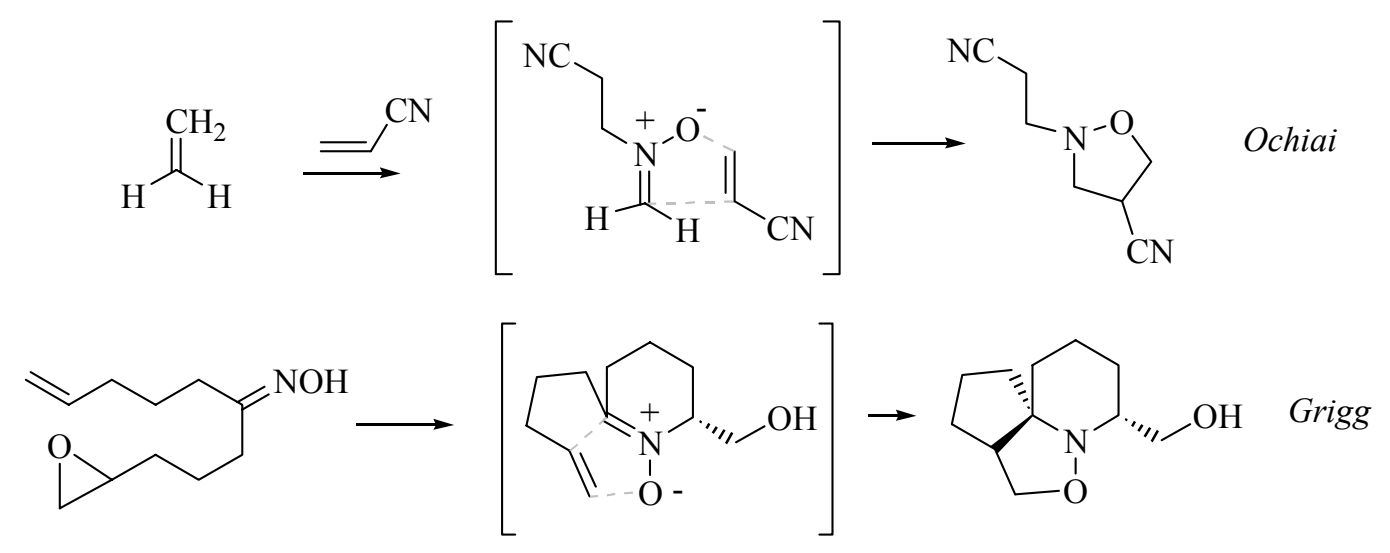

Scheme 2. Oxime derived nitrone dipolar cycloadditions.

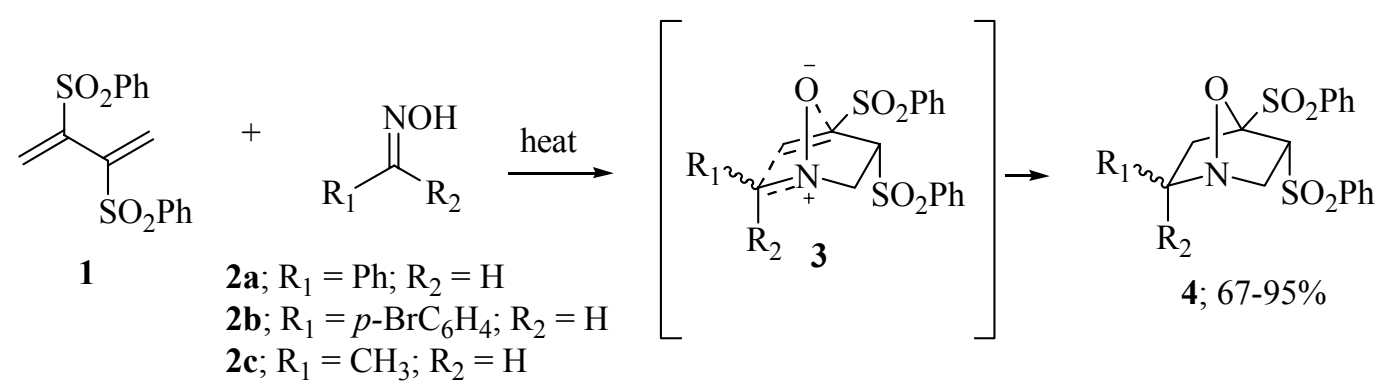

Scheme 3. Michael-addition/dipolar cycloaddition cascade of bis(phenylsulfonyl)diene $\mathbf{1}$.

We believe that the mechanism by which cycloadduct 4 is formed involves an initial conjugate addition of the oxime to one of the terminal $\pi$-bonds of the phenylsulfonyl substituted diene followed by a proton transfer to generate a transient nitrone (i.e. 3) which immediately undergoes a highly regiospecific dipolar cycloaddition reaction. In principle, the intramolecular cycloaddition reaction can proceed from two possible transition states (i.e. $\mathbf{3 A}$ and $\mathbf{3 B}$ ) which could result in the formation of two possible regioisomeric cycloadducts $4 \mathrm{~A}$ and $\mathbf{4 B}$ (Scheme 4). Molecular modeling calculations (MM2) were performed to determine the relative energies of the regioisomeric cycloadducts. ${ }^{20}$ These studies revealed that the preferential formation of the lower energy product $\mathbf{4 A}$ (relative to that of $4 \mathrm{~B}$ ) mimicked the energetic values of the transition states derived from nitrones $\mathbf{3 A}$ and $\mathbf{3 B}$, respectively. A cycloaddition product derived from the higher energy nitrone conformer $\mathbf{3 B}$ would have resulted in the formation of cycloadduct $\mathbf{4 B}$. However, this particular regioisomer has not been observed in any of the cases studied. 


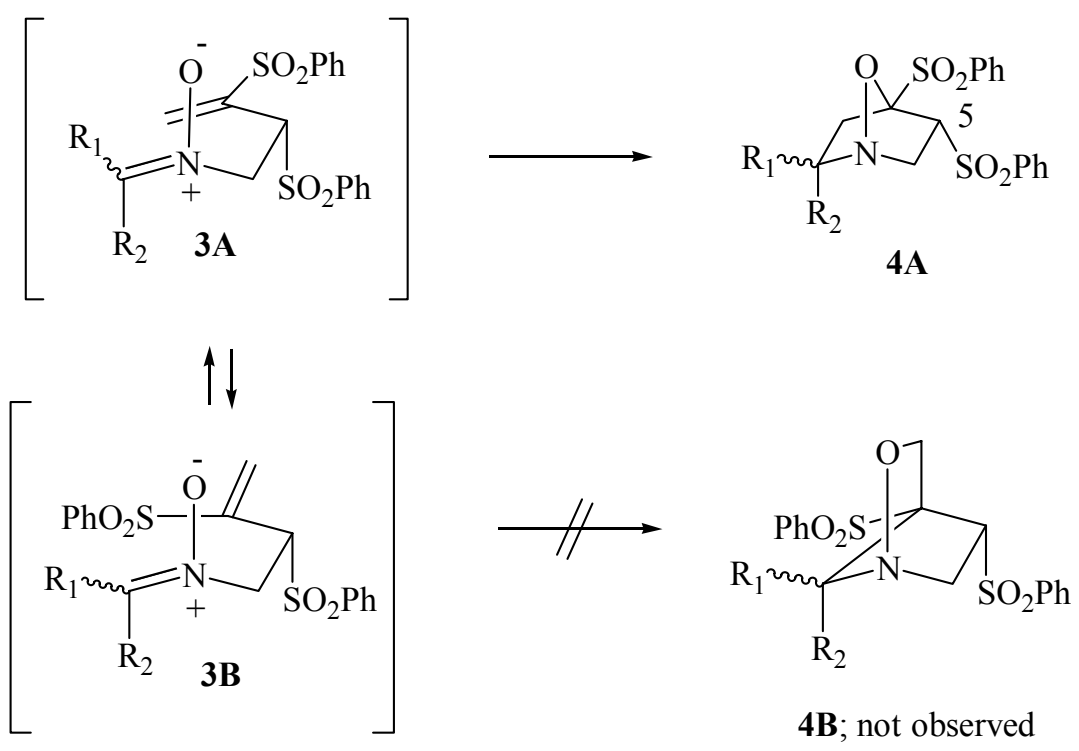

Scheme 4. Possible dipolar cycloaddition regiochemical outcomes.

Another interesting issue regarding the cycloaddition is that steric repulsion between the vicinal phenylsulfonyl groups is clearly responsible for the orientation of the sulfonyl group at the C-5 position of the resulting ring system. This large group resides exclusively in a pseudoaxial orientation about the ring system and this can be rationalized by assuming that the two bulky phenylsulfonyl groups tend to avoid any eclipsing interactions in the transition state for the cycloaddition. Steric repulsion forces the phenylsulfonyl group at C-5 to adopt a pseudoaxial orientation relative to the bicyclic system, thereby accounting for the stereospecificity of the reaction.

Subsequent work from our group showed that the resulting oxa-azabicyclic adducts 4 underwent smooth Raney-Ni reduction of the $\mathrm{N}-\mathrm{O}$ bond to provide 2,2-disubstituted piperidones of type 5 (Scheme 5). ${ }^{20}$ The remaining phenylsulfonyl group present in the initially formed piperidone 5 could be easily removed by treatment with an excess of tributyltin hydride ${ }^{21}$ and AIBN. The ensuing secondary amine was further derivatized using a wide assortment of different electrophiles $\left(\mathrm{R}_{3}-\mathrm{X}\right)$. The overall cascade sequence represents a high-yielding method for the preparation of a variety of 2,2-disubstituted piperidones. The easy accessibility of dienyl sulfone 1 led us to use this method for the synthesis of a number of alkaloid targets that are depicted in Scheme 6. Our efforts toward their construction are summarized in the following sections of this mini review article. 


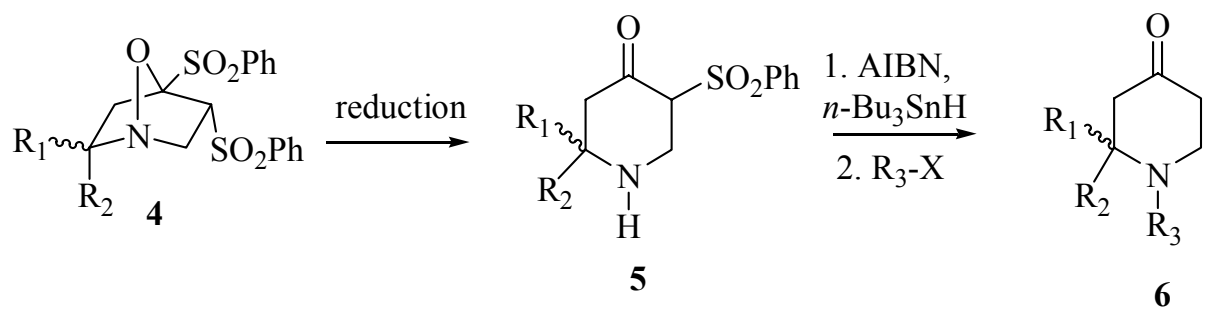

Scheme 5. Reduction of $\mathrm{N}-\mathrm{O}$ cycloadducts.

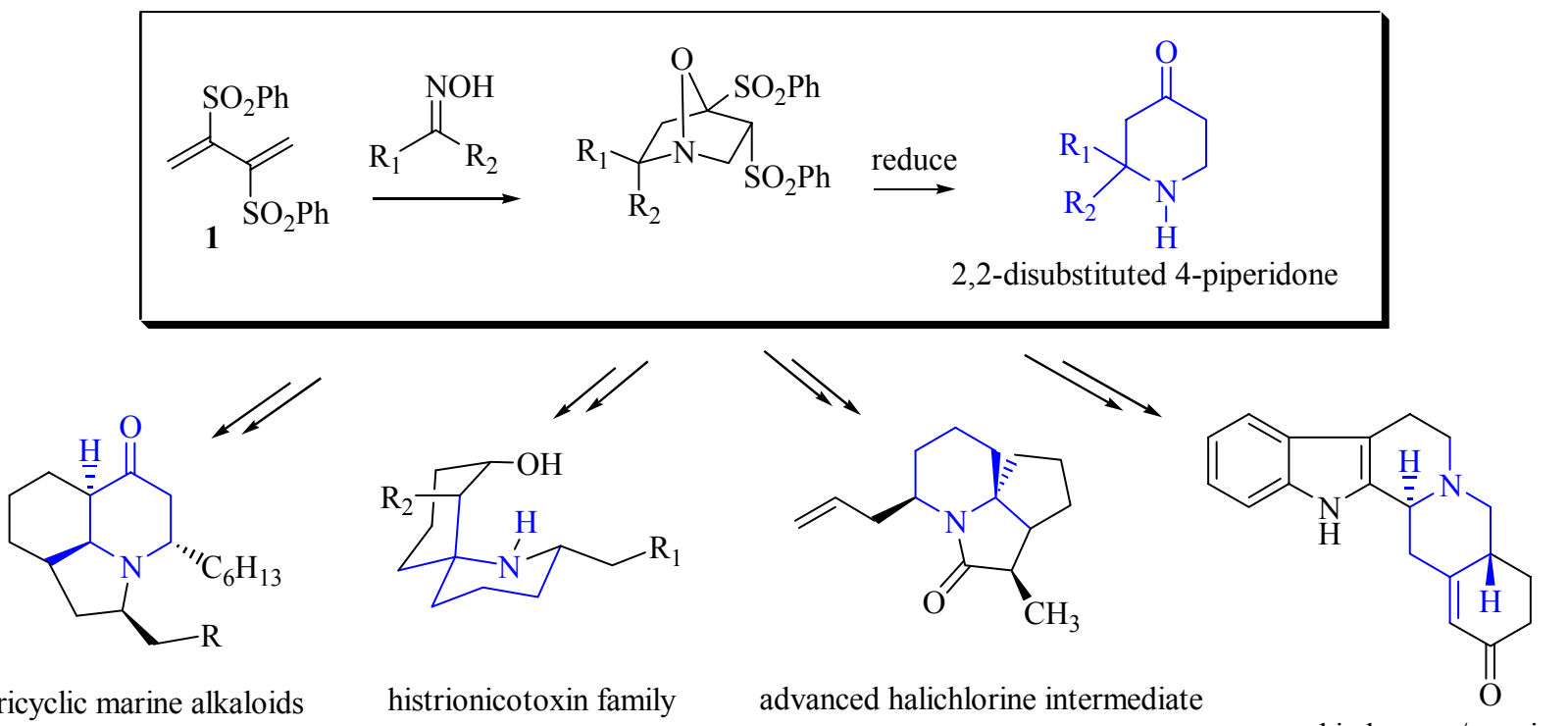

Scheme 6. Piperidine containing alkaloid targets arising from Michael addition/dipolar cycloaddition strategy.

\section{Alkaloid target synthesis}

\section{$3.1( \pm)$-Cylindricine $\mathbf{C}$}

The synthesis of the marine alkaloid $( \pm)$-cylindricine $\mathrm{C}^{22}$ by this strategy required the preparation of an oxime bearing side chains which would react in a differentiable manner (Scheme 7). ${ }^{23}$ 


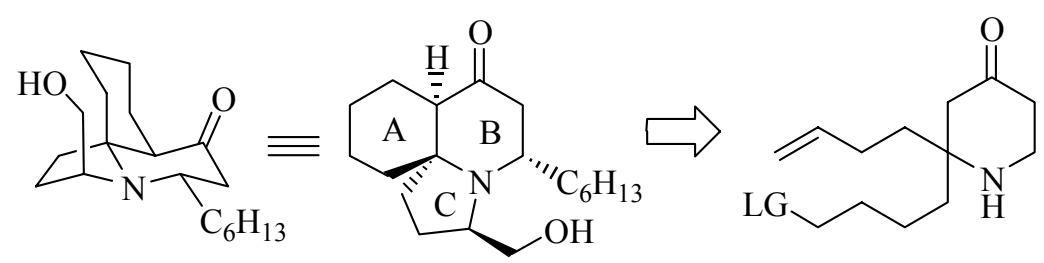

cylindricine $\mathrm{C}$
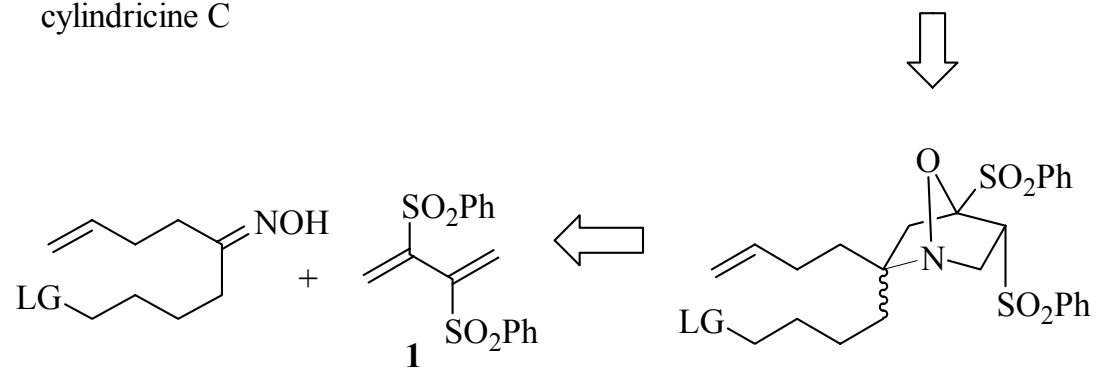

Scheme 7. Michael addition/dipolar cycloaddition approach to ( \pm )-cylindricine C.

Construction of the A- and C-rings of the cylindricine framework after the piperidonyl Bring can be realized by making use of the Michael addition-dipolar cycloaddition- reduction protocol. In practice, the requisite oxime 7 needed for the synthesis of cylindricine $\mathrm{C}$ was prepared in gram scale in $77 \%$ yield in four steps starting from $\delta$-valerolactone. Heating a sample of this oxime in the presence of phenylsulfonyldiene $\mathbf{1}$ afforded azaoxabicycle $\mathbf{8}$ as a 1:1 mixture of diastereomers in $75 \%$ yield. A modified Stack ${ }^{24}$ epoxidation protocol was then used to convert the terminal $\pi$-bond $\mathbf{8}$ into the corresponding epoxide 9. The stereoconfiguration of epoxide 9 most likely arises from a preferential approach of electrophilic oxygen onto the exoposition of alkene 8. The epoxidation presumably involves complexation of the manganese catalyst with the $\mathrm{N}-\mathrm{O}$ cycloadduct to direct the facial selectivity. Treatment of epoxide 9 with excess zinc dust ${ }^{25}$ triggered a reductive-cyclization cascade whereby $\mathrm{N}-\mathrm{O}$ bond scission was followed by spontaneous ejection of phenylsulfinic acid. Attack of the resulting secondary amine onto the pendant epoxide ring produces the 7-indolizidone ring system. Further reduction of the $\alpha$-keto phenylsulfonyl group occurred in situ and ultimately led to the formation of indolizidinone 11. This key azabicyclic alcohol was obtained in $76 \%$ yield as a 9:1 diastereomeric mixture from epoxide 9 and the major diastereomer possessed the required cylindricine $\mathrm{C}$ geometry at $\mathrm{C}-13$. The remaining $24 \%$ of recovered material corresponded to ketone 10. Further reduction of $\mathbf{1 0}$ with tributyltin hydride and AIBN provided an additional $20 \%$ of the diastereometerically pure alcohol 11 (Scheme 8 ). 

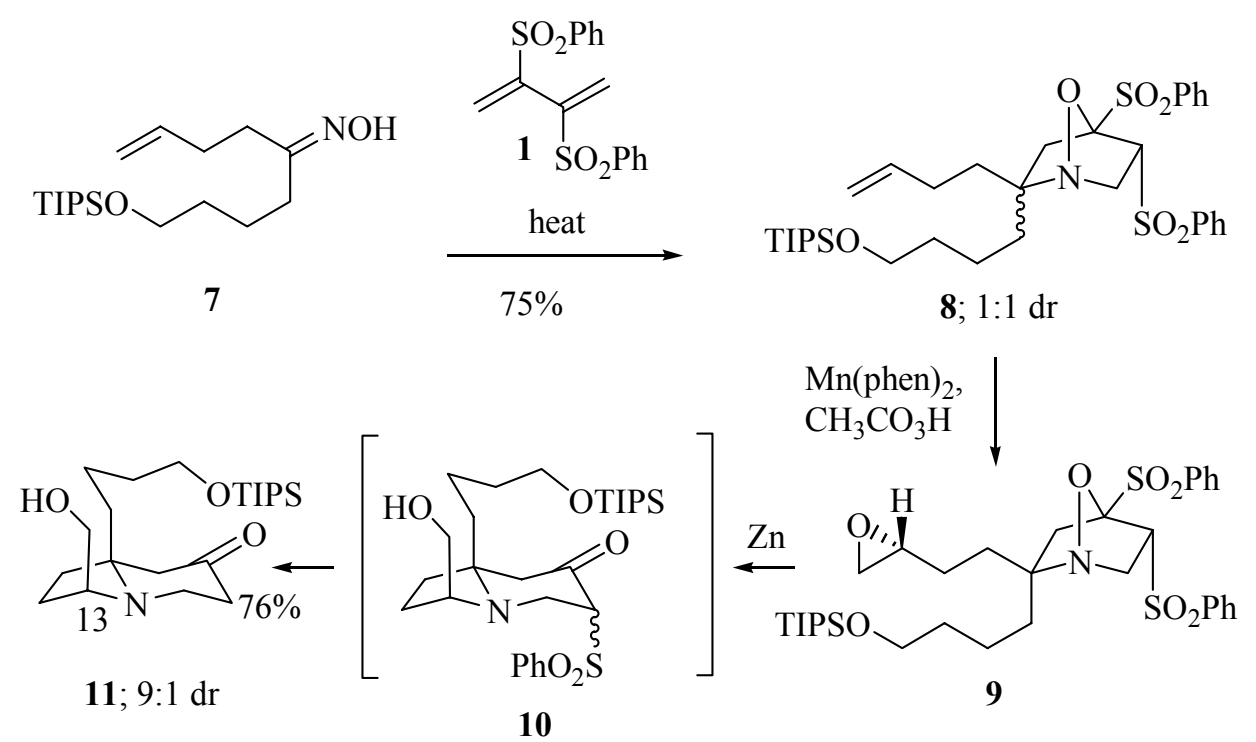

Scheme 8. Assembly of the BC-ring skeleton of cylindricine C.

The stereoenriched alcohol 11 was converted to the corresponding benzoyl ester at which point the minor diastereomer could be chromatographically removed. Desilylation of ester 12 produced alcohol 13 which was readily transformed into tosylate 14. Subjection of 14 to an intramolecular enolate alkylation reaction ${ }^{26}$ furnished the core azadecalin ring system 16. This reaction presumably proceeds through the intermediacy of the trans-azadecalin 15 which is readily epimerized to the thermodynamically more stable cis-conformation under the basic reaction conditions, ${ }^{27}$ thereby producing the required cylindricine configuration at C-5 (Scheme 9).

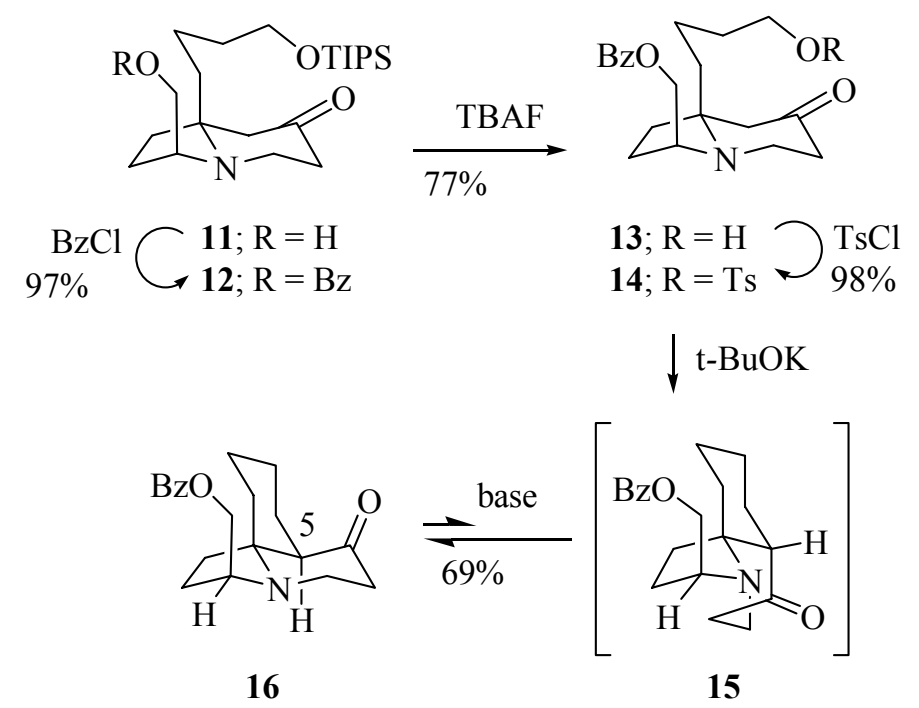

Scheme 9. Formation of ring-A for cylindricine C synthesis. 
Completion of the synthesis of $( \pm$-cylindricine $\mathrm{C}$ required an oxidation of $\mathbf{1 6}$ to the corresponding $2 \mathrm{H}$-piperidonyl enone $\mathbf{1 7}$ in order to incorporate the $n$-hexyl side chain at C-2 by an eventual cuprate conjugate addition. A variety of standard oxidative methods such as IBX, ${ }^{28}$ $\mathrm{PhSeCl}$ /oxidation, ${ }^{29}$ Saegusa, ${ }^{30}$ and $\alpha$-halo elimination failed to produce any synthetically useful quantity of enone 17. However, mercuric acetate eventually emerged as a superior reagent for introducing unsaturation into the 4-piperidone ring. ${ }^{31}$ The use of this oxidant resulted in a nearquantitative conversion of tricycle 16 to 2,3-dihydropyridinone 17 (Scheme 10). The tricyclic topography of $\mathbf{1 7}$ influenced attack of the cuprate reagent which occurred from the pseudoequatorial face of the conjugated $\pi$-array, 32 thereby installing the $n$-hexyl side chain into the desired stereochemical position at C-2.27,33 In order to complete the synthesis, saponification of the benzoyl ester furnished a chromatographically-separable mixture of $( \pm)$-cylindricine $\mathrm{C} 18$ and 2-epi-cylindricine C 19 in 90\% overall conversion from 2,3-dihydropyridinone 17.

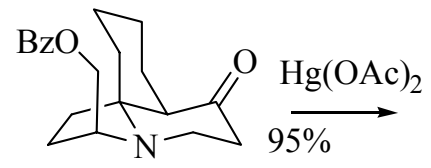

16

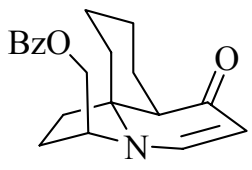

17

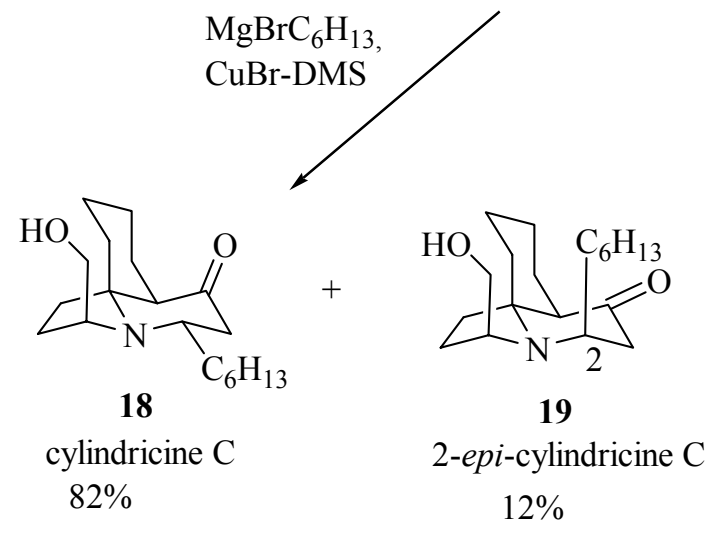

Scheme 10. Final Approach to ( \pm )-cylindricine $C$.

\subsection{Approach to the perhydrohistrionicotoxin (PHTx) core}

Azaspirocyclic alkaloids isolated from the skin extracts of the neotropical frog Dendrobates histrionicus have emerged as important neurophysiological probes owing to their unusual effects as selective inhibitors of the neuromuscular, ganglionic, and nACh receptors. ${ }^{34,35}$ The unique neurophysiological properties associated with the skeleton of this class of alkaloids have prompted numerous synthetic approaches towards the azaspiro[5.5] undecane core of perhydrohistrionicotoxin (PHTx). ${ }^{36,37}$ Studies in our laboratory demonstrated that the tandem Michael addition-dipolar cycloaddition cascade utilizing 2,3-bis(phenylsulfonyl)butadiene 1 represents a very efficient strategy for producing a functionalized azaspiro[5.5] undecane scaffold capable of being transformed into 2,7,8-epi-perhydrohistrionicotoxin 20. The synthesis of this 
alkaloid was envisaged to arise from cuprate addition onto 2,3-dihydropyridinone 21 . The latter compound could be formed from the spirocyclic adduct $\mathbf{2 2}$ derived from the Michael additiondipolar cycloaddition cascade. Guided by this synthetic approach, the assembly of an oxime related to $\mathbf{2 3}$ was undertaken (Scheme 11). ${ }^{38}$

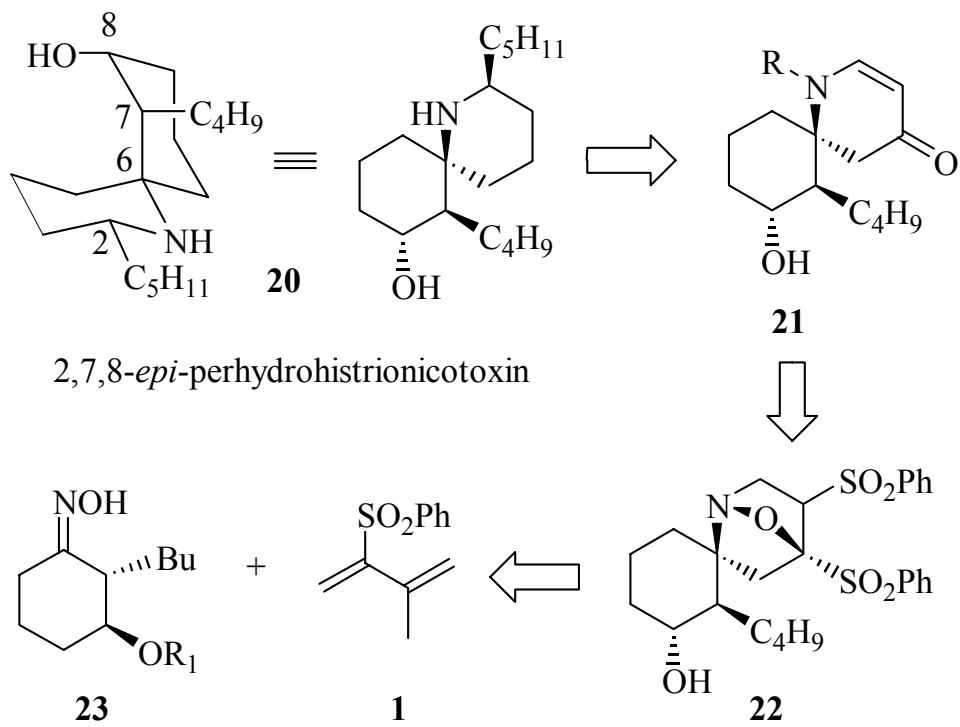

Scheme 11. Michael addition/dipolar cycloaddition approach to ( \pm )-2,7,8-epiperhydrohistrionicotoxin.

By following a protocol originally developed by Wender, ${ }^{39}$ ketones $\mathbf{2 4}$ and $\mathbf{2 5}$ were used to set the C-7 and C-8 stereochemistry of the final target. These ketones were prepared using the silyl 24 and methoxymethyl 25 protected alcohols. Thus, reaction of these two compounds with hydroxylamine hydrochloride furnished the desired oximes $\mathbf{2 6}$ and $\mathbf{2 7}$ in excellent yields. When these oximes were allowed to react with phenylsulfonyldiene $\mathbf{1}$, the expected silylated cycloadducts $\mathbf{2 8 a}$ and $\mathbf{2 8 b}$ were formed as a 3:2-mixture of diasteromers in $72 \%$ overall yield (Scheme 12).

X-ray analysis of cycloaducts $\mathbf{2 8 a}$ and $\mathbf{2 8 b}$ indicated that the 1,3-dipolar cycloaddition had proceeded with complete stereocontrol, but gave the undesired stereochemistry at the C-7 and C8 stereocenters of histrionicotoxin. However, by adopting an epimerization protocol previously reported by Godleski, ${ }^{40}$ we were able to adjust these stereocenters at a later stage of the synthesis. Since the diastereomeric mixture of cycloadducts $\mathbf{2 8 a} / \mathbf{b}$ differed only in terms of the orientation of the oxido bridge and $\mathrm{C}_{3}$ sulfonyl stereochemistry (both of which would be destroyed during the reductive cleavage step), separation of this mixture was deemed unnecessary. Unfortunately, all our attempts to carry out a reductive $\mathrm{N}-\mathrm{O}$ cleavage of the mixture of cycloadducts $\mathbf{2 8 a} / \mathbf{b}$ were unsuccessful, leading only to recovered starting material or decomposition products. In contrast to the silylated cycloadducts $\mathbf{2 8 a} / \mathbf{b}, \mathrm{N}-\mathrm{O}$ bond reduction of the less-hindered MOM-protected cycloadducts $\mathbf{2 9 a / b}$ did proceed smoothly when treated with 
sodium mercury amalgam, giving piperidone $\mathbf{3 0}$ in $69 \%$ yield, accompanied by a small amount of the over-reduced product 31. Further reductive desulfonylation of $\mathbf{3 0}$ provided more of the key aza-spiropiperidone 31 in excellent yield. Reaction of the secondary amine with benzoyl chloride gave amide 32 which was converted to 2,3-dihydropyridinone $\mathbf{3 3}$ by means of Saegusa oxidation. ${ }^{41}$ Introduction of the final stereocenter was carried out by conjugate addition of copper complexed-pentylmagnesium bromide onto the $\pi$-system of the vinylogous amide 33 . This reaction provided piperidone $\mathbf{3 4}$ in excellent yield. The stereochemical configuration about the newly formed C-2 carbon center of $\mathbf{3 4}$ could not be easily determined through conventional NMR spectroscopic techniques, necessitating preparation of a crystalline derivative for X-ray analysis. Thus, condensation of $\mathbf{3 4}$ with tosyl hydrazine afforded the the corresponding hydrazone $\mathbf{3 5}$ (Scheme 13) ${ }^{38} \mathrm{X}$-ray analysis of $\mathbf{3 5}$ confirmed that the 1,4-cuprate addition to $\mathbf{3 3}$ had given rise to the correct axial side chain stereochemistry at C-2. This result can be attributed to the steric constraints imposed by the dihydropyridinone ring $\mathbf{3 3}$ which results in an axial trajectory for $n$-pentyl addition to $\pi$-array. ${ }^{42}$ Control of the configuration at C-2 of ketone 34 represented an opportunity to specifically prepare the PHTx derivative 2,7,8-epiperhydrohistrionicotoxin. Toward this end, trapping the enolate anion derived from ketone $\mathbf{3 4}$ with $N$-phenyltriflamide ${ }^{43}$ followed by subsequent catalytic hydrogenation resulted in the facile removal of the carbonyl functionality at C-4. This was followed by LAH reduction which provided benzylamine 36. The MOM ether group was removed to give alcohol $\mathbf{3 7}$ in good yield, which upon hydrogenolysis of the benzyl group completed the total synthesis of ( \pm )-2,7,8-epiperhydrohistrionicotoxin $\mathbf{2 0}$ (Scheme 14).

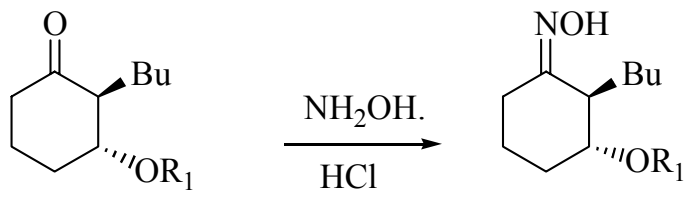

$$
\begin{array}{ll}
\mathbf{2 4} ; \mathrm{R}_{1}=\mathrm{TBS} & \mathbf{2 6} ; \mathrm{R}_{1}=\operatorname{TBS}(94 \%) \\
\mathbf{2 5} ; \mathrm{R}_{1}=\text { MOM } & \mathbf{2 7} ; \mathrm{R}_{1}=\operatorname{MOM}(96 \%)
\end{array}
$$

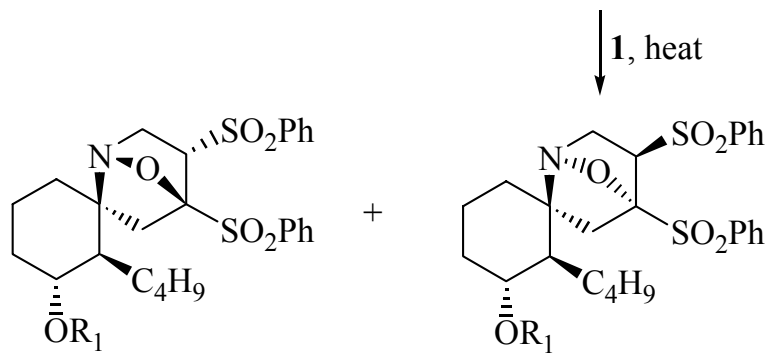

28a/b; $\mathrm{R}_{1}=$ TBS (72\%)

29a/b; $\mathrm{R}_{1}=\operatorname{MOM}(82 \%)$

Scheme 12. Oxa-azacycle formation. 


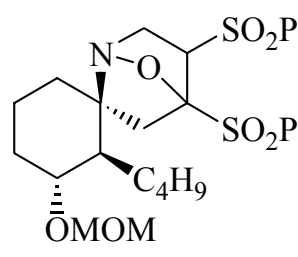

29a/b

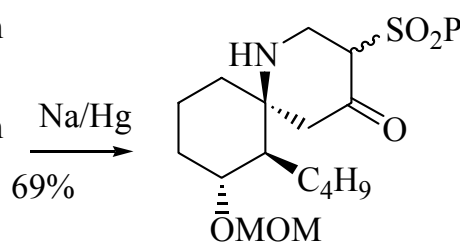

30 $\underset{82 \%}{\stackrel{\substack{\mathrm{AIBN}, \mathrm{Bu}_{3} \mathrm{SnH}}}{\longrightarrow}}$

31

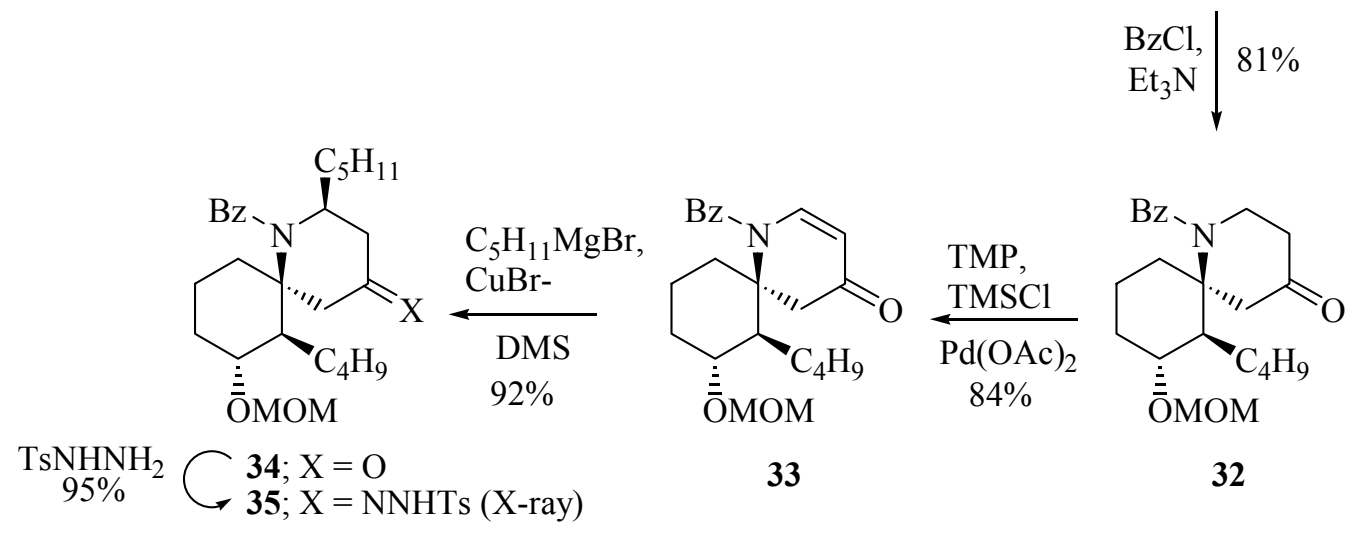

Scheme 13. Oxazacycle reductive $\mathrm{N}-\mathrm{O}$ cleavage and $n$-pentyl installation.

This particular route to 2,7,8-epi-PHTx also represents an excellent opportunity to intercept several intermediates previously reported by the Godleski ${ }^{40}$ and Corey 44 groups en route to $( \pm)$ deamyl-PHTx and $( \pm)$-PHTx. In this regard, ketone 32 was first converted to the corresponding enol triflate prior to catalytic hydrogenation and was then subjected to LAH reduction to furnish benzylamine 38 (Scheme 15). Trimethylsilylbromide-mediated MOM deprotection provided Godleski alcohol 39, thereby formally intercepting this investigator's route to ( \pm )-deamyl-PHTx 40. ${ }^{40}$ The isolation of intermediate 39 also represents an indirect formal synthesis of $( \pm)$-PHTx since this same compound had been previously synthesized from $( \pm)$-deamyl-PHTx $\mathbf{4 0}$ by Corey and co-workers in the mid 1970s. ${ }^{44}$

\subsection{Synthesis of benzo[a]quinolizine and indolo[a]quinolizine scaffolds}

Because of their clinical importance as anti-hyertensive agents, alkaloids isolated from the WestAfrican evergreen Pausinystalia yohimbe have emerged as important pharmacological agents, particularly the pentacyclic alkaloid $( \pm)$-yohimbenone 42.45 The roots derived from $C$. ipecacuanha have been used for centuries as an emetic, and have also been found to show antiamoebic activity. 46 As part of our research employing cascade strategies for alkaloid synthesis, we felt that the tandem Michael addition-dipolar cycloaddition cascade had high potential of being utilized as an entry to this class of alkaloids. The advantage of this reaction platform is that it generates a vestigial phenylsulfonyl group (i.e. 43 and 47) that allows for further synthetic elaboration through site-specific enolate chemistry. As an initial model for an eventual yohimbenone synthesis, we first undertook a formal synthesis of $( \pm$ )-emetine (Scheme 16). 47 


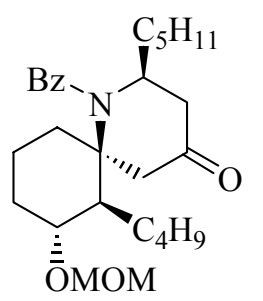

34

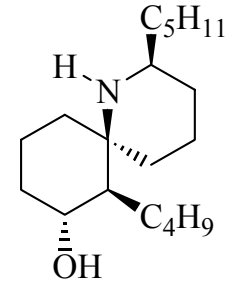

20

2,7,8-epi-PHTx

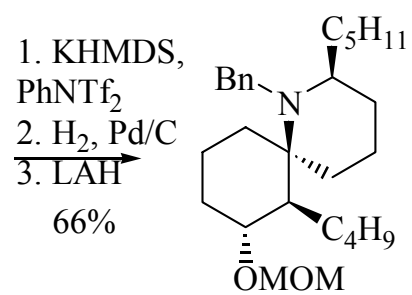

TMSBr $\downarrow^{36} 74 \%$

$\frac{\mathrm{H}_{2}, \mathrm{Pd} / \mathrm{C}}{98 \%}$

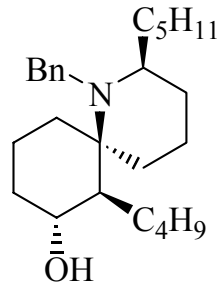

37

Scheme 14. Final approach to ( \pm )-2,7,8-epi-perhydrohistrionicotoxin.<smiles>CC[C@H]1[C@@H](OC)CCC[C@@]12CC(=O)CCN2C(=O)c1ccccc1</smiles>

32
KHMDS,

$\underset{\mathrm{H}_{2}, \mathrm{Pd} / \mathrm{C}}{\stackrel{\mathrm{PhNT}_{2}}{\longrightarrow}}$

$\mathrm{LAH}$

$74 \%$ $\mathrm{TMSBr} \downarrow 74 \%$

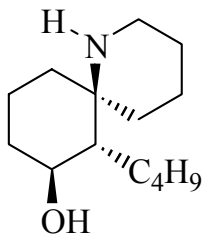

ref \#40<smiles>CCCCCCCCCCCC[C@H]1[C@@H](O)CCC[C@@]12CCCCN2Cc1ccccc1</smiles>

39

38

$$
\begin{aligned}
& \text { 40; (+/-)-deamyl-PHTx } \\
& \text { 41; (+/-)-PHTx }
\end{aligned} \text { ref \#44 }
$$<smiles>CCCCC[C@H]1[C@@H](OC)CCC[C@@]12CCCCN2Cc1ccccc1</smiles> 


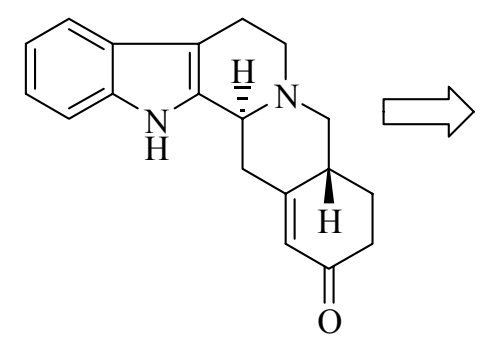

42; yohimbenone

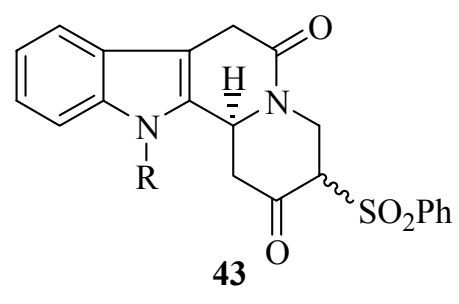

\

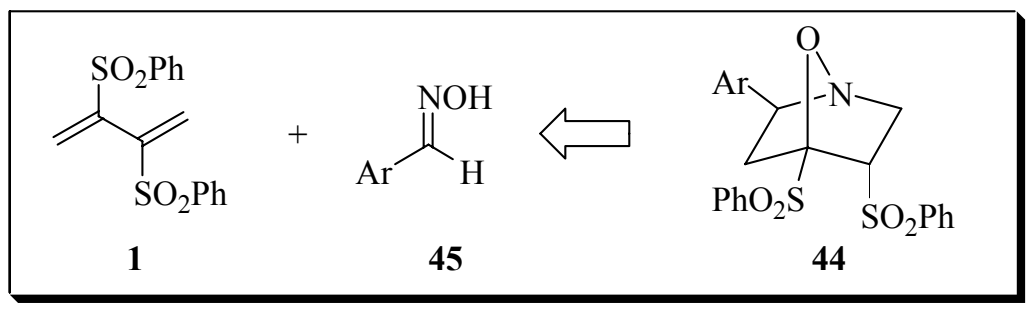

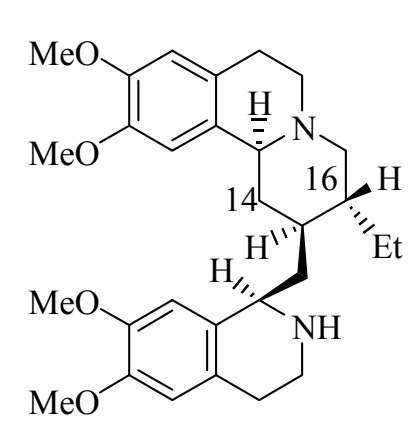

46; emetine

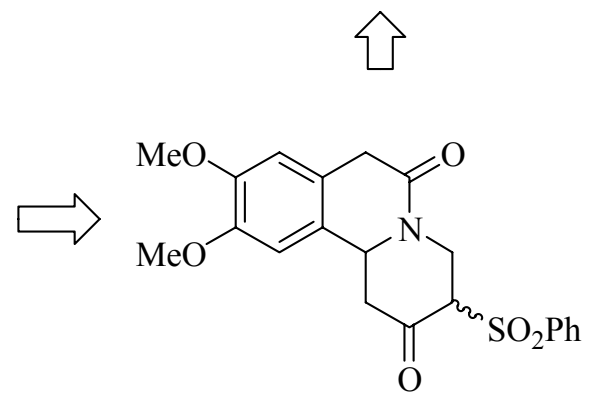

47

Scheme 16. Approaches to ( \pm )-yohimbenone and $( \pm)$-emetine.

Oxime 48 was readily available from commercial 2-(3,4-dimethoxyphenyl)acetic acid and was treated with phenylsulfonyldiene 1 so as to generate cycloadduct 49 (80\% yield). By analogy to previous results encountered with several aldehyde oximes, the aryl group prefers to exist in an endo-orientation in the newly formed cycloadduct 49 (Scheme 17).

Subjection of cycloadduct 49 to reduction using Raney nickel under an atmosphere of hydrogen triggered a cyclization cascade sequence whereby cleavage of the $\mathrm{N}-\mathrm{O}$ bond was followed by spontaneous intramolecular acylation of the nitrogen atom with the proximal ester group to furnish 47 in excellent yield as a 1:1-mixture of diastereomers. In order to obtain synthetically useful quantities of the required late-stage intermediates, the key Robinson annulation reaction relied upon a specific order of operations. 48 Thus, conjugate addition of methyl vinyl ketone (MVK) in the presence of catalytic triethylamine to 47 afforded a 1:1mixture of the diastereomeric ketones $\mathbf{5 0}$ in $80 \%$ yield. ${ }^{49}$ A tin-mediated phenylsulfonyl reduction of $\mathbf{5 0}$ furnished $\mathbf{5 1}$ as a 1:1-mixture of diastereomeric amides. Finally, subjection of $\mathbf{5 1}$ to an intramolecular aldol condensation-dehydration sequence using sodium methoxide gave rise to a 5:1-mixture of diastereomeric tetracycles 52. The major diastereomer corresponded to that of 
the natural configuration of the alkaloid emetine, and this was confirmed by X-ray crystallographic analysis (Scheme 18).

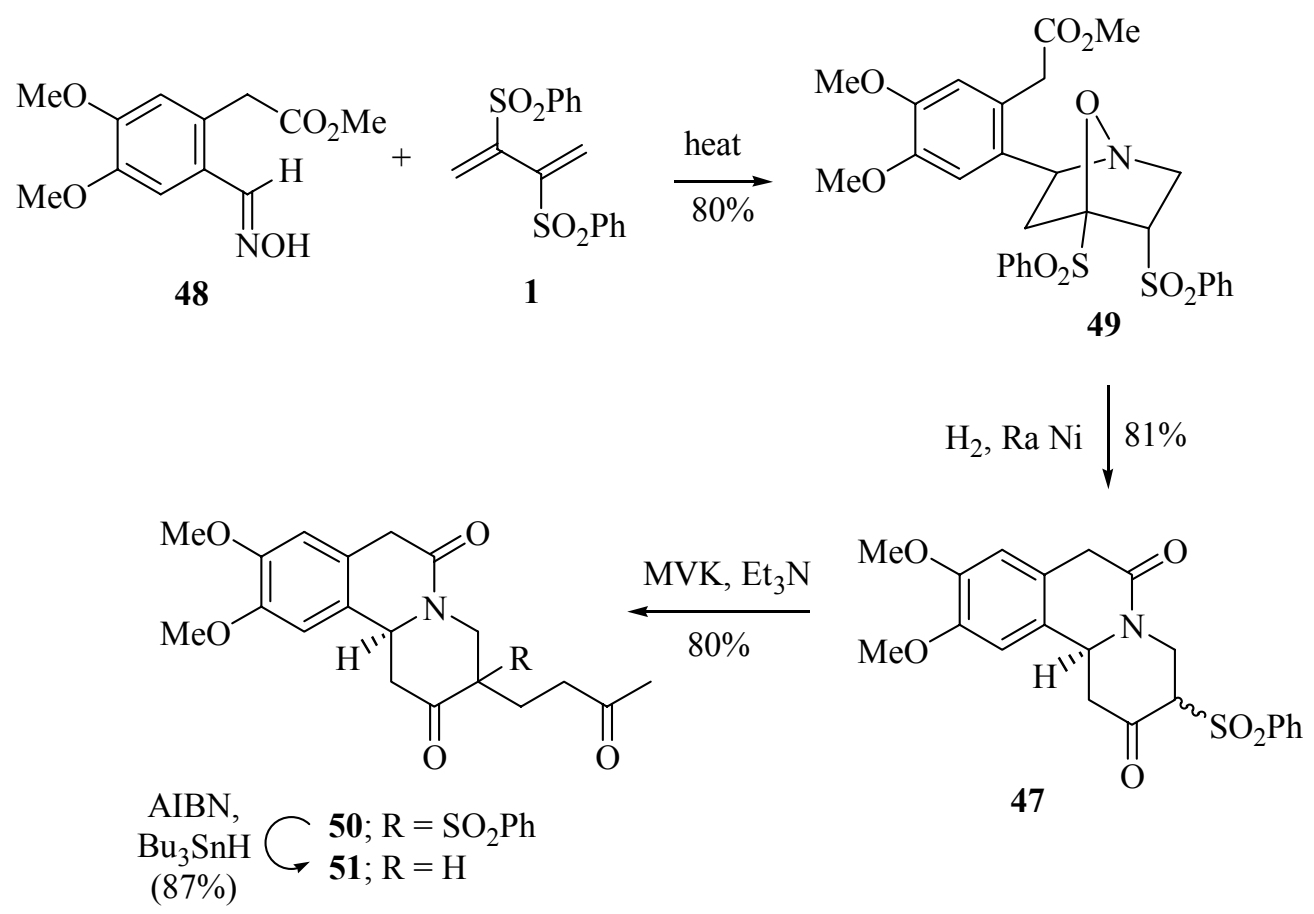

Scheme 17. Michael-addition/dipolar cycloaddition approach to ( \pm )-emetine.

The 5:1-mixture of diastereomers was easily separated chromatographically and the major isomer 52 was subjected to LAH reduction which not only reduced the amide carbonyl group, but also delivered an over-reduced allylic alcohol as an undesired side product. ${ }^{50}$ However, a subsequent manganese oxidation of the crude reduction mixture cleanly converted the mixture to the known Takano enone 53,51,52 thereby resulting in a formal synthesis of $( \pm$ )-emetine. The related alkaloid $( \pm$ )-yohimbenone was also synthesized using a similar approach. Thus, treatment of oxime 54 with phenylsulfonyl diene 1 resulted in a smooth conjugate addition/dipolar cycloaddition cascade to produce cycloadduct 55 in $72 \%$ yield. Reductive $N-O$ cleavage of 55 using Pearlman's catalyst with acetic acid in ethyl acetate under an atmosphere of hydrogen gas afforded the key ABCD yohimbenone construct 56 in $81 \%$ yield as a 2:1-mixture of diastereomers. As was the case in the emetine synthesis, methyl vinyl ketone was added to compound 56 and this was followed by reductive removal of the phenylsulfonyl group to furnish 57 in excellent yield for the overall sequence of reactions. Unlike the emetine approach, we found that pyrrolidine was much more efficient than sodium methoxide for converting $\mathbf{5 7}$ into the desired Robinson product 58. With formation of the E-ring secured, amide reduction of 58 followed by a oxidation of the allylic alcohol and a subsequent debenzylation using $\mathrm{AlCl}_{3}$ gave ( \pm )-yohimbenone $\mathbf{4 2}$ in $72 \%$ yield for the three step sequence (Scheme 19). 


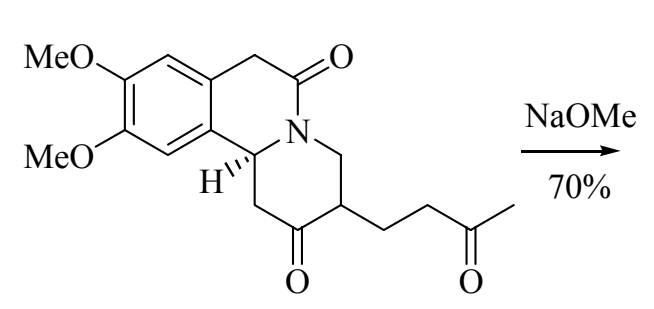

51

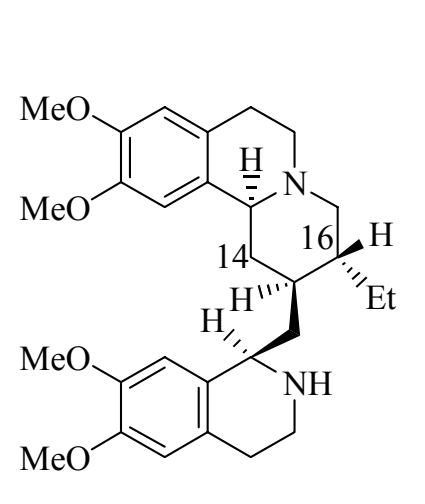

46; emetine<smiles>COc1cc2c(cc1OC)[C@H]1CC3=CC(=O)CC[C@H]3CN1C(=O)C2</smiles>

52; X-ray

\begin{tabular}{l|l}
$\mathrm{LAH}$ \\
$\mathrm{MnO}_{2}$ &
\end{tabular}

ref \# 46

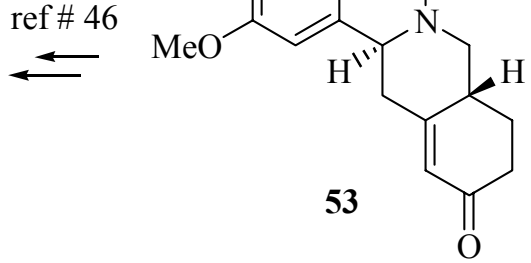

Scheme 18. Robinson annulation and formal synthesis of $( \pm)$-emetine.

\subsection{Preparation of the azatricyclic core of $( \pm)$-halichlorine}

Since Danishefsky first reported the total synthesis of halichlorine $\mathbf{5 9}$ in 1999,53,54 a flurry of synthetic efforts devoted to accessing this naturally occurring marine alkaloid have been reported. 55 While the primary alkaloid isolated from the marine sponge Halichondria okadai Kadota exhibits remarkable vascular cell inhibition, ${ }^{56,57}$ sub-structures of this complex natural product, particularly in the azacyclic-containing region of the molecule, have garnered the attention of several research groups. As a consequence of our interests in using cascade chemistry for alkaloid synthesis, a Michael addition/dipolar cycloaddition cascade was envisioned as a method to access an advanced intermediate reported by Feldman $\mathbf{6 2},{ }^{58}$ which would constitute a formal synthesis of $( \pm$ )-halichlorine 59 (Scheme 20). 

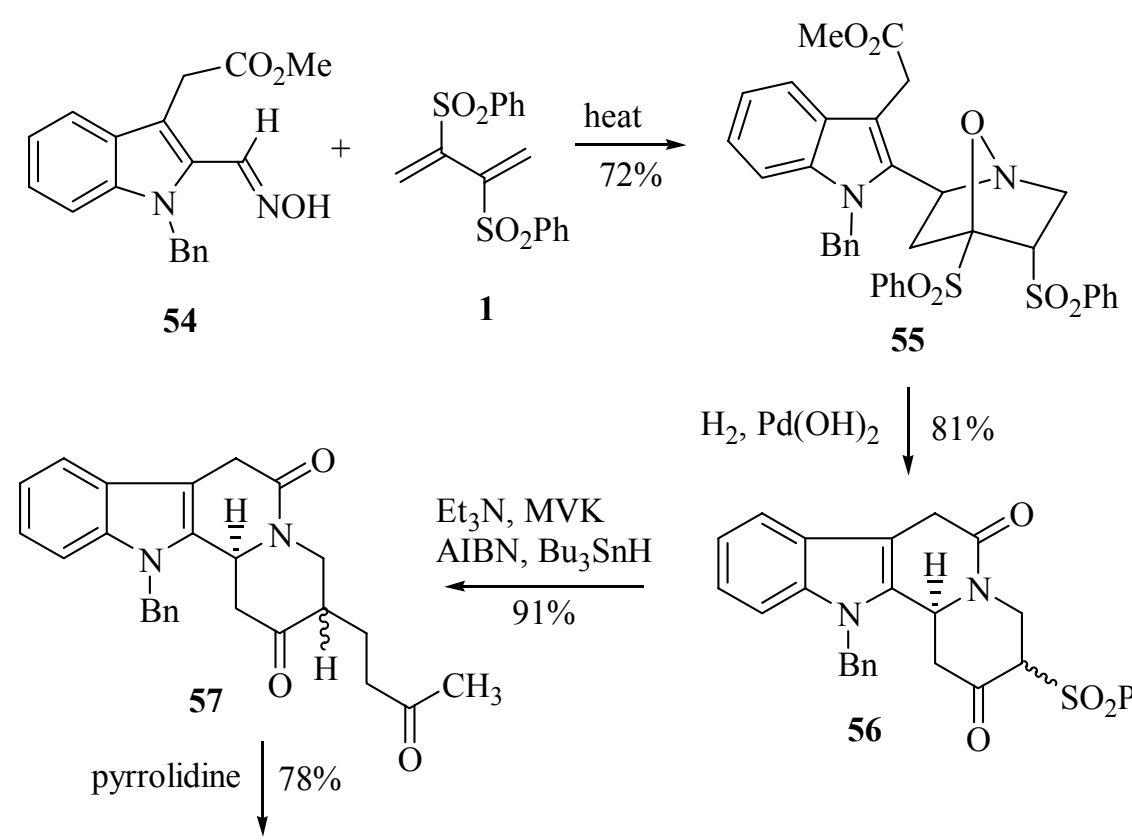

$\mathrm{H}_{2}, \mathrm{Pd}(\mathrm{OH})_{2} \downarrow 81 \%$
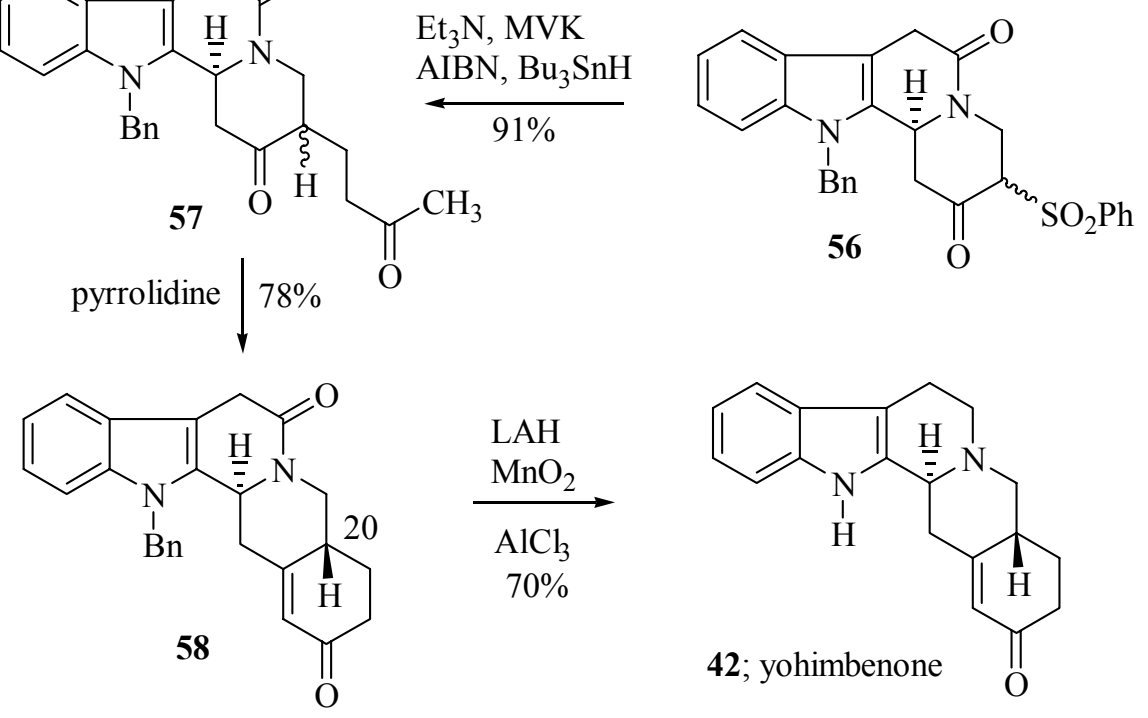

Scheme 19. Total synthesis of $( \pm)$-yohimbenone

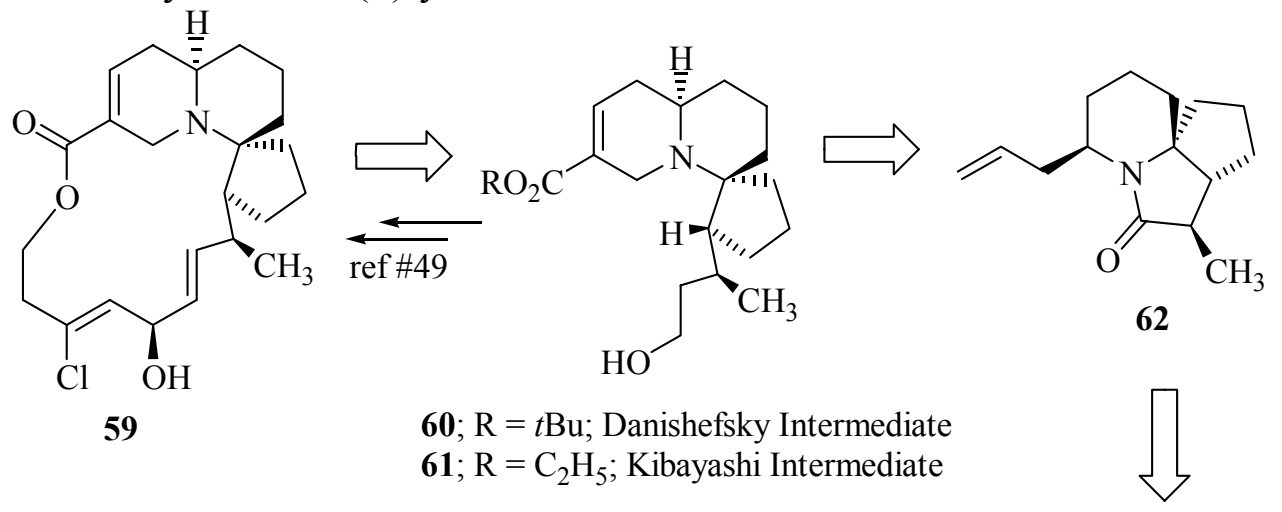

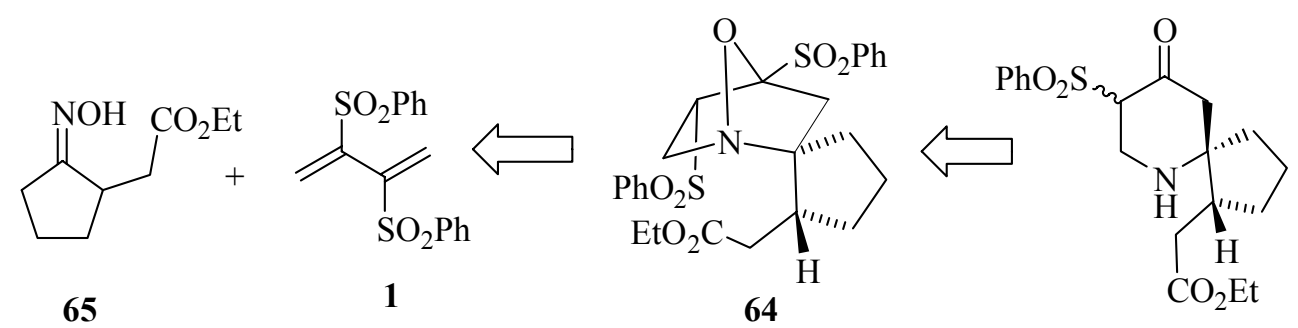

63

Scheme 20. Michael addition/dipolar cycloaddition entry to the ( \pm )-halichlorine azacyclic core. 
In order to establish the feasibility of this approach toward halichlorine, oxime $\mathbf{6 5}$ was prepared and treated with phenylsulfonyldiene 1 which afforded a 1.3:1-mixture of the diastereomers of the expected cycloadducts (i.e. 66 and 67) in 95\% yield (Scheme 21). ${ }^{59}$

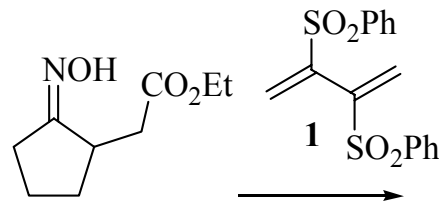

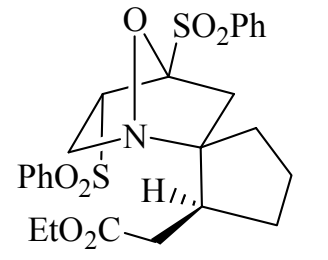

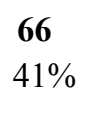

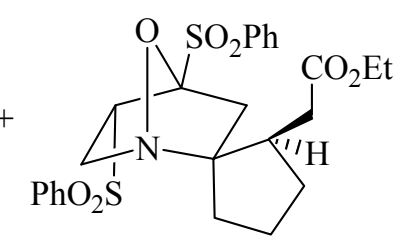

67

$54 \%$

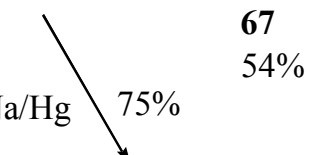<smiles>O=C1C=CN2C(=O)C[C@H]3CCC[C@H]3[C@@H]12</smiles>

70

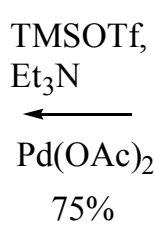

$75 \%$

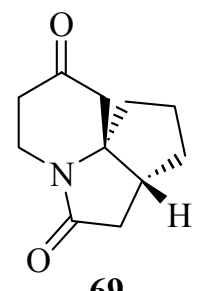

69
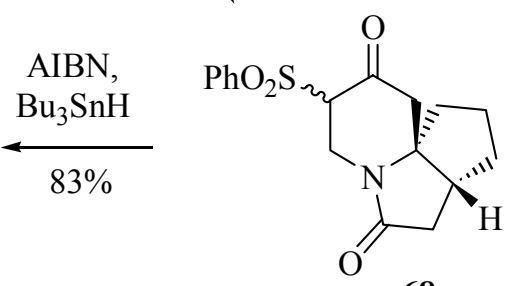

68

Scheme 21. Dienyl sulfone entry into $( \pm)$-halichlorine tricyclic enone core.

The mixture was reduced with sodium mercury amalgam in order to cleave the $\mathrm{N}-\mathrm{O}$ bridge. After the reduction occurred, the resulting secondary amine underwent spontaneous intramolecular acylation to furnish azatricyclic $\mathbf{6 8}$ as a mixture of diastereomers. Desulfonylation using tributyltin hydride and AIBN followed by a Saegusa oxidation gave the vinylogous amide 70. This 2,3-dihydropyridinone proved to be somewhat resistant to conventional 1,4-addition using a variety of organometallic reagents, preferring to give the alternative 1,2-addition product instead. However, conjugate addition to the $\beta$-carbon of $\mathbf{7 0}$ was eventually achieved via the addition of allyl stannane in the presence of TMSOTf which furnished 71 in 78\% yield as a 15:1mixture of diastereomers. The preferred configuration at the C-5 position arises by approach of the nucleophilic reagent from the convex face of 70, setting the requisite geometry at this carbon center. The keto group in $\mathbf{7 1}$ was protected as the 1,3-dithiane in order to allow for exclusive methylation at the $\gamma$-lactam position. Thus, reaction of the enolate anion derived from amide $\mathbf{7 2}$ with methyl iodide gave rise to the methylated amide $\mathbf{7 3}$ derived by attack from the least hindered face of 72. The resulting dithiane was reduced with tributyltin hydride and AIBN to furnish Feldman's intermediate 62,58 which had previously been taken on to $( \pm$ )-halichlorine 59 (Scheme 22). 
<smiles>O=C1C=CN2C(=O)C[C@H]3CC[C@H]1[C@H]32</smiles>

70<smiles>C=CC[C@H]1CC(=O)[C@@H]2CC[C@@H]3CC(=O)N1[C@H]32</smiles>

71

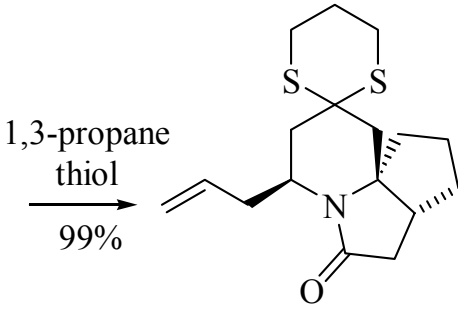

72

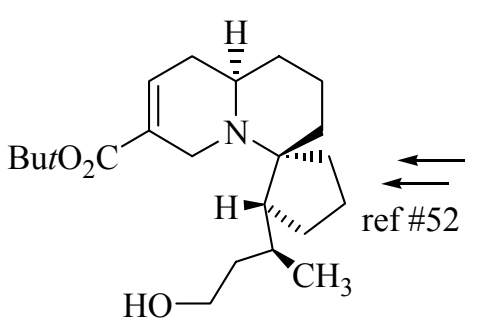

60; Danishefsky Intermediate<smiles>C=CC[C@@H]1CCCC23CCC[C@H]2C(C)C(=O)N13</smiles>

62

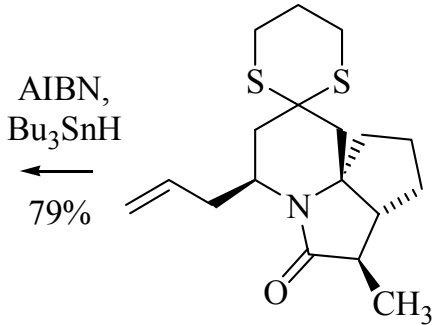

73

Scheme 22. Final approach to azatricyclic skeleton of $( \pm)$-halichlorine.

\section{Conclusions}

In conclusion, tandem cycloaddition chemistry continues to be of great interest both mechanistically and synthetically. The many structurally diverse and highly successful examples of heterocyclic ring formation cited in this mini-review clearly indicate that tandem cycloaddition cascades have evolved as an important strategy in heterocyclic synthesis. In particular the alkaloid targets summarized in this article have been achieved through the use of a Michael addition-dipolar cycloaddition cascade using bis-2,3-diphenylsulfonylbutadiene and this approach represents a versatile and easy entry to 2,2-disubstituted piperidone and piperidinecontaining systems.

\section{Acknowledgments}

We greatly appreciate the financial support provided by the National Science Foundation (Grant CHE-0742663). 


\section{References}

1. (a) Dake, G. Tetrahedron 2006, 62, 3467. (b) Ciufolini M. A. Farmaco 2005, 60, 627. (c) Sinclair, A.; Stockman, R. A. Nat. Prod. Rep. 2007, 24, 298. (d) Schar, P.; Cren, S.; Renaud, P. Chimia 2006, 60, 131. (e) Grigg, R. Chem. Soc. Rev. 1987, 16, 89. (f) Hewlett, N. M.; Hupp, C. D.; Tepe, J. J. Synthesis 2009, 2825. (g) Osterhout, M. H.; Nadler, W. R.; Padwa, A. Synthesis 1994, 123. (h) Wee, A. G. H. Curr. Org. Synth. 2006, 3, 499. (i) Lee, A. W. M.; Chan, W. H.; Zhang, H. K.; Xia, P. F. Curr. Org. Chem. 2003, 7, 573. (j) Confalone, P. N. J. Heterocycl. Chem. 1990, 27, 31. (k) de Meijere, A.; Kozhushkov, S. I.; Khlebnikov, A. F. Top. Curr. Chem. 2000, 207, 89. ( 1) Padwa, A. Chem. Soc. Rev. 2009, 38, 3072. (m) De Meijere, A.; Kozhushkov, S. I. Eur. J. Org. Chem. 2000, 3809. (n) Nair, V.; Suja, T. D. Tetrahedron 2007, 63, 12247. (o) Coldham, I.; Hufton, R. Chem. Rev. (Washington, DC, U. S.) 2005, 105, 2765.

2. Chiacchio, U.; Padwa, A.; Romeo, G. Curr. Org. Chem. 2009, 13, 422.

3. (a) Synthetic Applications of 1,3-Dipolar Cycloaddition Chemistry Toward Heterocycles and Natural Products; Padwa, A., Pearson, W. H., Eds.; Wiley: New York, 2003. Huisgen, R. In 1,3-Dipolar Cycloaddition Chemistry; Padwa, A., Ed.; Wiley: New York, 1984; Vol. $1, \mathrm{p} 1$.

4. Curran, D. P. Advances in Cycloaddition, JAI Press Inc., Greenwich, Ct. 1990. Schmidt, R. R. Acc. Chem. Res, 1986, 19, 250; Waldmann, H. Synthesis 1994, 535.

5. Cordero, F. M.; Pisaneschi, F.; Batista, K. M.; Valenza, S.; Machetti, F.; Brandi, A. J. Org. Chem. 2005, 70, 856.

6. (a) Padwa, A.; Schoffstall, A. M. In Advances in Cycloaddition; Curran, D., Ed.; JAI: Greenwich, CT, 1990, 2. (b) Caruthers,W. R. Cycloadditions in Organic Synthesis; Pergamon: London, 1990, Chapter 6, p 269. (c) Black, D. C. S.; Cozier, R. F.; Davis, V. C. Synthesis 1975, 205.

7. Jørgensen, K. A. Angew, Chem., Int. Ed. Engl. 2000, 39, 3559.

8. (a) Tietze, L. F., Beifuss, U. Angew, Chem., Int. Ed. Engl. 1993, 32, 131. (b) Nicolaou, K. C.; Chen, J. S. Chem. Soc. Rev. 2009, 38, 2993. (c) Nicolaou, K. C.; Edmonds, D. J.; Bulger, P. G. Angew. Chem., Int. Ed. 2006, 45, 7134. (d) Bur, S. K.; Padwa, A. Adv. Heterocycl. Chem. 2007, 94, 1.

9. Padwa, A.; Bur, S. K. Tetrahedron 2007, 63, 5341.

10. (a) Danishefsky, S. Acc. Chem. Res. 1981, 14, 400. (b) Grayson, J. I.; Petrzilka, M. Synthesis 1981, 753. (c) Hickmott, P. W. Tetrahedron 1984, 40, 2989.

11. (a) Evans, D. A.; Bryan, C. A.; Sims, C. L. J. Am. Chem. Soc. 1972, 94, 2891. (b) Trost, B. M.; Vladuchick, W. C.; Bridges, A. J. J. Am. Chem. Soc. 1980, 102, 3554. (c) Cohen, T.; Kosaych, Z. J.Org. Chem. 1982, 47, 4005.

12. (a) Halazy, S.; Magnus, P. Tetrahedron Lett. 1984, 1421. (b) Posner, G. H.; Wettlaufer, D. G. J. Am. Chem. Soc. 1986,108, 7373. (c) Posner, G. H.; Harrison, W. J. Chem. Soc., Chem. Commun. 1985, 1786. 
13. (a) Akermark, B.; Nystrom, J. E.; Rein, T.; Backvall, J. E.; Helquist, P.; Aslanian, R. Tetrahedron Lett. 1984, 25, 5719. (b) Bloom, A. J.; Mellor, J. M. Tetrahedron Lett. 1986, $27,873$.

14. Organic Chemistry of Sulfur; Oae, S., Ed.; Plenum: New York, 1977. Bernardi, F.; Mangini, E. Organic Sulfur Chemistry: Theoretical and Experimental Advances; Elsevier: Amsterdam, 1985.

15. Padwa, A.; Watterson, S. H.; Ni, Z. Org. Synth. 1997, 74, 115.

16. (a) Padwa, A.; Filipkowski, M. A. Tetrahedron Lett. 1993, 34, 813. (b) Padwa, A.; Filipkowski, M. A.; Meske, M.; Murphree, S. S.; Watterson, S. H.; Ni, Z. J. J. Org. Chem. 1994, 59, 588. (c) Padwa, A.; Meske, M.; Murphree, S. S.; Watterson, S. H.; Ni, Z. J. Am. Chem. Soc. 1995, 117, 7071. (d) Padwa, A.; Gareau, Y.; Harrison, B.; Norman, B. H. J. Org. Chem. 1991, 56, 2713. (e) Padwa, A.; Norman, B. H. J. Org. Chem. 1990, 55, 4801. (f) Inagaki, F.; Mukai, C. Org. Lett. 2006, 8, 1217. (g) Ohno, M.; Shirakawa, Y.; Eguchi, S. Synthesis 1998, 1812. (h) Barnwell, N.; Beddoes, R. L.; Mitchell, M. B.; Joule, J. A. Heterocycles 1994, 37, 175.

17. Okamura, W. H.; Jeganathan, S. Tetrahedron Lett. 1982, 23, 4673.

18. Ochiai, M.; Obayashi, M.; Morita, K. Tetrahedron 1967, 23, 2641.

19. (a) Armstrong, P.; Grigg, R.; Surendrakumar, S.; Warnock, W. J. J. Chem. Soc., Chem. Commun. 1987, 1327. (b) Armstrong, P.; Grigg, R.; Warnock, W. J. J. Chem. Soc., Chem. Commun. 1987, 1325. (c) Grigg, R.; Markandu, J. Tetrahedron Lett. 1989, 30, 5489. (d) Grigg, R.; Markandu, J.; Surendrakumar, S. Tetrahedron Lett. 1990, 31, 1191.

20. (a) Norman, B. H.; Gareau, Y.; Padwa, A. J. Org. Chem. 1991, 56, 2154. (b) Padwa, A.; Norman, B. H. Tetrahedron Lett. 1988, 29, 2417.

21. (a) Trost, B. M. Acc. Chem. Res. 1978, 11, 453. (b) Trost, B. M. Chem. Rev. 1978, 78, 363.

(c) Truce, W. E.; Klinger, T. C.; Brand, W. W. In Organic Chemistry of Sulfur; Oae, S., Ed.; Plenum: New York, 1977; 527. (d) DeLucchi, O.; Pasquato, L. Tetrahedron 1988, 44, 4755.

(e) Paquette, L. A.; Lin, H.; Gunn, B. P.; Coghlan, M. J. J. Am. Chem. Soc. 1988, 110, 5818.

(f) Magnus, P. D. Tetrahedron 1977, 33, 2019. (g) Durst, T. In Comprehensive Organic Chemistry; Barton, D. R., Ollis, W. D., E\&.; Pergamon: Oxford, 1979; Vol. 3, 197.

22. (a) Blackman, A. J.; Li, C.; Hockless, D. C. R.; Skelton, B. W.; White, A. H. Tetrahedron 1993, 49, 8645. (b) Li, C.; Blackman, A. J. Aust. J. Chem. 1994, 47, 1355. (c) Li, C.; Blackman, A. J. Aust. J. Chem. 1995, 48, 955.

23. (a) Flick, A. C.; Caballero, M. J. A.; Padwa, A. Tetrahedron, 2010, 66, 3643. (b) Flick, A. C.; Caballero, M. J. A.; Padwa, A. Org. Lett. 2008, 10, 1871.

24. (a) Terry, T. J.; Dubois, G.; Murphy, A.; Stack, T. D. P. Angew. Chem. Int. Ed. 2007, 46, 945. (b) Murphy, A.; Stack, T. D. P. J. Mol. Catal. A. 2006, 251, 78. (c) Murphy, A.; Pace, A.; Stack, T. D. P. Org. Lett. 2004, 6, 3119. (d) Dubois, G.; Murphy, A.; Stack, T. D. P. Org. Lett. 2003, 5, 2469. (e) Murphy, A.; Dubois, G.; Stack, T. D. P. J. Am. Chem. Soc. 2003, 125,5250 .

25. White, J. D.; Hansen, J. D. J. Org. Chem. 2005, 70, 1963. 
26. (a) Vite, G. D.; Spencer, T. A. J. Org. Chem. 1988, 53, 2555. (b) Conia, J. M.; Rouessac, F. Tetrahedron 1961, 16, 45.

27. (a) Liu, J.; Hsung, R. P.; Peters, S. D. Org. Lett. 2004, 6, 3989. (b) Liu, J.; Swidorski, J. J.; Peters, S. D.; Hsung, R. P. J. Org. Chem. 2005, 70, 3898. (c) Trost, B. M.; Rudd, M. T. Org. Lett. 2003, 5, 4599. (d) Wang, J.; Swidorski, J. J.; Sydorenko, N.; Hsung, R. P.; Coverdale, H. A.; Kuyava, J. M.; Liu, J. Heterocycles 2006, 70, 423. (e) Werner, K. M.; De los Santos, J. M.; Weinreb, S. M.; Shang, M. J. Org. Chem. 1999, 64, 4865.

28. (a) Nicolaou, K. C.; Montagnon, T.; Baran, P. S. Angew. Chem., Int. Ed. 2002, 41, 993. (b) Nicolaou, K. C.; Montagnon, T.; Baran, P. S.; Zhong, Y. L. J. Am. Chem. Soc. 2002, 124 , 2245. (c) Nicolaou, K. C.; Zhong, Y. L.; Baran, P. S. J. Am. Chem. Soc. 2000, 122, 7596.

29. Liotta, D.; Saindane, M.; Barnum, C.; Zima, G. Tetrahedron 1985, 41, 4881.

30. (a) Hu, X.-D.; Tu, Y. Q.; Zhang, E.; Gao, S.; Wang, S.; Wang, A.; Fan, C.-A.; Wang, M. Org. Lett. 2006, 8, 1823. (b) Porth, S.; Bats, J. W.; Trauner, D.; Giester, G.; Mulzer, J. Angew. Chem., Int. Ed. 1999, 38, 2015.

31. (a) Flick, A. C.; Padwa, A. Arkivoc 2009, (vi), 4. (b) Flick, A. C.; Padwa, A. Tetrahedron Lett. 2008, 49, 5739.

32. Donohoe, T. J.; Johnson, D. J.; Mace, L. H.; Bamford, M. J.; Ichihara, O. Org. Lett. 2005, 7 , 435.

33. (a) Canesi, S.; Bouchu, D.; Ciufolini, M. A. Angew. Chem., Int. Ed. 2004, 43, 4336. (b) Ciufolini, M. A.; Canesi, S.; Ousmer, M.; Braun, N. A. Tetrahedron 2006, 62, 5318. (c) Swidorski, J. J.; Wang, J.; Hsung, R. P. Org. Lett. 2006, 8, 777.

34. (a) Witkop, B. Experientia 1971, 27, 1121. (b) Daly, J. W.; Karle, I.; Meyers, W.; Tokuyama, T.; Waters, J. A.; Witkop, B. Proc. Natl. Acad. Sci. U.S.A. 1971, 68, 1870. (c) Tokuyama, T.; Venoyama, K.; Brown, G.; Daly, J. W.; Witkop, B. Helv. Chim. Acta 1974, 57, 2597. (d) Karle, I. J. Am. Chem. Soc. 1973, 95, 4036. (e) Daly, J. W.; Spande, T. F.; Whittaker, N.; Highet, R. J.; Feigl, D.; Nishimori, N.; Tokuyama, T. J. Nat. Prod. 1986, 49, 265. (f) Daly, J. W. J. Nat. Prod. 1998, 61, 162.

35. (a) Lapa, A. J.; Albuquerque, J.; Sarvey, J.; Daly, J. W.; Witkop, B. Exp. Neurol., 1975, 47, 558. (b) Takahashi, T.; Witkop, B.; Brossi, A.; Maleque, M. A.; Albuquerque, E. X. Helv. Chim. Acta 1982, 65, 252. (c) Spivak, C. E.; Maleque, M. A.; Oliveria, A. C.; Masukawa, M.; Tokuyama, J.; Daly, J. W.; Albuquerque, E. X. Mol. Pharmacol. 1982, 21, 351.

36. (a) Daly, J. W. in Progress in the Chemistry of Natural Products; Hem, W., Grisebach, H., Kirby, G., Eds.; Springer-Verlag: Vienna, 1982, 41, 206. (b) Witkop, B.; Gossinger, E. The Alkaloids; Brossi, A., Ed.; Academic Press: London, 1983, 21, 139. (c) Inubushi, Y.; Ibuka, T. Heterocycles 1982, 17, 507.

37. For an excellent recent review on synthetic approaches to the histrionicotoxin family of alkaloids, see: Sinclair, A.; Stockman, R. A. Nat. Prod. Rep. 2007, 24, 298.

38. Wilson, M. S.; Padwa, A. J. Org. Chem. 2008, 73, 9601.

39. Wender, P. A.; Erhardt, J. M.; Letendre, L. J. J. Am. Chem. Soc. 1981, 103, 2114. 
40. Godleski, S. A.; Heacock, D. J.; Meinhart, J. D.; Wallendael, S. V. J. Org. Chem. 1983, 48, 2101.

41. Ito, Y.; Hirao, T.; Saegusa, T. J. Org. Chem. 1978, 43, 1011.

42. This result is consistent with the findings of Comins and co-workers with related $N$-acyl-2,3dihydro-4-pyridones: (a) Comins, D. L.; Brown, J. D. Tetrahedron Lett. 1986, 27, 4549. (b) Brown J. D.; Foley, M. A.; Comins, D. L. J. Am. Chem. Soc. 1988, 110, 7445. (c) Comins, D. L.; LaMunyon, D. H. Tetrahedron Lett. 1989, 30, 5053. (d) Comins, D. L.; Dehghani, A. Tetrahedron Lett. 1991, 32, 5697. (e) Comins, D. L.; Dehghani, A. J. Org. Chem. 1995, 60, 794. (f) Comins, D. L.; LaMunyon, D. H.; Chen, X. J. Org. Chem. 1997, 62, 8182. (g) Kranke, B.; Hebrault, D.; Schultz-Kukula, M.; Kunz, H. Synlett 2004, 671.

43. Carreňo, M. C.; Garcia-Cerrada, S.; Urbano, A. Chem. Eur. J. 2003, 9, 4118.

44. Corey, E. J.; Arnett, J. F.; Widiger, G. N. J. Am. Chem. Soc. 1975, 97, 430.

45. For review on the yohimboid alkaloids, see: (a) The Alkaloids, Chemistry and Physiology; Manske, R. H. F., Ed.; Academic: New York, 1981; Saxton, J. E. In Specialist Periodical Reports, The Alkaloids; The Royal Society of Chemistry, Burlington House: London, 1983, 13, 221. (b) Cordell, G. A Introduction to Alkaloids, A Biogenetic Approach; WileyInterscience: New York, 1981; 574.

46. (a) The Isoquinoline Alkaloids: Chemistry and Pharmacology. Shamma, M., Blomquist, A. T., Wasserman, H., Me.; Academic Press: New York, 1972, p 25. (b) Fuji, T.; Ohba, M. in The Alkaloids 1989, 22, 1. (c) Ihara, M.; Yasui, K.; Taniguchi, N.; Fukumoto, K. J. Chem. Soc., Perkin Trans. 1 1990, 1469. (d) The Isoquinoline Alkaloids; Bentley, K. W., Ed.; Pergamon Press: New York, 1965.

47. Stearman, C. J.; Wilson, M. S.; Padwa, A. J. Org. Chem. 2009, 74, 3491.

48. For a review, see: Gawley, R. H. Synthesis 1976, 777.

49. Rosenmund, P.; Brandt, B.; Flecker, P.; Eberhard, H. Lieb. Ann. Chem. 1990, 9, 857.

50. Burgstahler, A. W.; Bithos, Z. J. J. Am. Chem. Soc. 1960, 82, 5466.

51. (a) Takano, S.; Hatakeyama, S.; Ogasawara, K. Tetrahedron Lett. 1978, 2519. (b) Takano, S.; Sasaki, M.; Kanno, H.; Shishido, K.; Ogasawara, K. Heterocycles 1977, 7, 143. (c) Takano, S.; Takahashi, Y.; Hatakeyama, S.; Ogasawara, K. Heterocycles 1979, 12, 765.

52. Takano, S.; Sasaki, M.; Kanno, H.; Shishido, K.; Ogasawara, K. J. Org. Chem. 1978, 43, 4169.

53. (a) Danishefsky, S. J.; Inoue, M.; Trauner, D. Ernst Schering Res. Found. Workshop 2000, 32, 1. (b) Trauner, D.; Churchill, D. G.; Danishefsky, S. J. Helv. Chim. Acta 2000, 83, 2344.

(c) Trauner, D.; Danishefsky, S. J. Tetrahedron Lett. 1999, 40, 6513.

54. Trauner, D.; Schwarz, J. B.; Danishefsky, S. J. Angew. Chem., Int. Ed. 1999, 38, 3542.

55. (a) Andrade, R. B.; Martin, S. F. Org. Lett. 2005, 7, 5733. (b) Arini, L. G.; Szeto, P.; Hughes, D. L.; Stockman, R. A. Tetrahedron Lett. 2004, 45, 8371. (c) Christie, H. S.; Heathcock, C. H. Proc. Natl. Acad. Sci. U. S. A. 2004, 101, 12079. (d) Clive, D. L. J.; Wang, J.; Yu, M. Tetrahedron Lett. 2005, 46, 2853. (e) Clive, D. L. J.; Yeh, V. S. C. Tetrahedron Lett. 1999, 40, 8503. (f) Clive, D. L. J.; Yu, M.; Li, Z. Chem. Commun. (Cambridge, U. K.) 
2005, 906. (g) de Sousa, A. L.; Pilli, R. A. Org. Lett. 2005, 7, 1617. (h) Feldman, K. S. Strategies Tactics Org. Synth. 2004, 4, 133. (i) Hurley, P. B.; Dake, G. R. J. Org. Chem. 2008, 73, 4131. (j) Huxford, T.; Simpkins, N. S. Synlett 2004, 2295. (k) Keck, G. E.; Heumann, S. A. Org. Lett. 2008, 10, 4783. (1) Keen, S. P.; Weinreb, S. M. J. Org. Chem. 1998, 63, 6739. (m) Kim, H.; Seo, J. H.; Shin, K. J.; Kim, D. J.; Kim, D. Heterocycles 2006, 70, 143. (n) Koviach, J. L.; Forsyth, C. J. Tetrahedron Lett. 1999, 40, 8529. (o) Lee, S.; Zhao, Z. Tetrahedron Lett. 1999, 40, 7921. (p) Lee, S.; Zhao, Z. Org. Lett. 1999, 1, 681. (q) Liu, D.; Acharya, H. P.; Yu, M.; Wang, J.; Yeh, V. S. C.; Kang, S.; Chiruta, C.; Jachak, S. M.; Clive, D. L. J. J. Org. Chem. 2009, 74, 7417. (r) Matsumura, Y.; Aoyagi, S.; Kibayashi, C. Org. Lett. 2003, 5, 3249. (s) Matsumura, Y.; Aoyagi, S.; Kibayashi, C. Org. Lett. 2004, 6, 965. (t) Shindo, M.; Fukuda, Y.-I.; Shishido, K. Tetrahedron Lett. 2000, 41, 929. (u) Takasu, K.; Ohsato, H.; Ihara, M. Org. Lett. 2003, 5, 3017. (v) Wright, D. L.; Schulte, J. P.; Page, M. A. Org. Lett. 2000, 2, 1847. (w) Yang, S.-H.; Clark, G. R.; Caprio, V. Org. Biomol. Chem. 2009, 7, 2981. (x) Yokota, W.; Shindo, M.; Shishido, K. Heterocycles 2001, 54, 871. (y) Yu, M.; Clive, D. L. J.; Yeh, V. S. C.; Kang, S.; Wang, J. Tetrahedron Lett. 2004, 45, 2879. (z) Zhang, H.-L.; Zhao, G.; Ding, Y.; Wu, B. J. Org. Chem. 2005, 70, 4954.

56. (a) Arimoto, H.; Hayakawa, I.; Kuramoto, M.; Uemura, D. Tetrahedron Lett. 1998, 39, 861.

(b) Kuramoto, M.; Tong, C.; Yamada, K.; Chiba, T.; Hayashi, Y.; Uemura, D. Tetrahedron Lett. 1996, 37, 3867.

57. (a) Itoh, M.; Kuwahara, J.; Itoh, K.; Fukuda, Y.-I.; Kohya, M.; Shindo, M.; Shishido, K. Bioorg. Med. Chem. Lett. 2002, 12, 2069. (b) Kita, M.; Uemura, D. Top. Heterocycl. Chem. 2006, 6, 157. (c) Kuramoto, M.; Arimoto, H.; Uemura, D. Mar. Drugs 2004, 2, 39. (d) Tsubosaka, Y.; Murata, T.; Kinoshita, K.; Yamada, K.; Uemura, D.; Hori, M.; Ozaki, H. Eur. J. Pharmacol., 628, 128.

58. Feldman, K. S.; Perkins, A. L.; Masters, K. M. J. Org. Chem. 2004, 69, 7928.

59. Flick, A. C.; Caballero, M. J. A.; Lee, H. I.; Padwa, A. J. Org. Chem. 2010, 75, 1992. 